\title{
Nanoparticles And Human Saliva: A Step Towards Drug Delivery Systems For Dental And Craniofacial Biomaterials
}

This article was published in the following Dove Press journal: International Journal of Nanomedicine

\author{
Rafal Pokrowiecki (iD ${ }^{1-3}$ \\ Jacek Wojnarowicz (iD) 4 \\ Tomasz Zareba (iD) ${ }^{2}$ \\ Iwona Koltsov id ${ }^{4}$ \\ Witold Lojkowski iD ${ }^{4}$ \\ Stefan Tyski iD ${ }^{2,5}$ \\ Agnieszka Mielczarek (iD) 6 \\ Pawel Zawadzki iD ' \\ 'Department of Cranio-Maxillofacial \\ Surgery, Oral Surgery and Implantology, \\ Medical University of Warsaw, Warsaw, \\ Poland; ${ }^{2}$ Department of Antibiotics and \\ Microbiology, National Medicines \\ Institute, Warsaw, Poland; ${ }^{3}$ Private \\ Practice, Warsaw, Poland; ${ }^{4}$ Institute of \\ High Pressure Physics, Polish Academy of \\ Sciences, Warsaw, Poland; ${ }^{5}$ Department \\ of Pharmaceutical Microbiology, Medical \\ University of Warsaw, Warsaw, Poland; \\ ${ }^{6}$ Department of Conservative Dentistry, \\ Medical University of Warsaw, Warsaw, \\ Poland
}

\begin{abstract}
Aim: The aims of this study were to investigate new nano-formulations based on $\mathrm{ZnO}$ and Ag nanoparticle (NP) compounds when used against clinical strains of oral gram-positive and gram-negative bacteria, and to examine the stability and behaviour of nano-formulation mixtures in saliva based on different compositions of Ag NPs, $\mathrm{ZnO}$ NPs and $\mathrm{ZnO}+\mathrm{x} \cdot \mathrm{Ag}$ NPs. Methods: ZnO NPs with and without nanosilver were obtained by microwave solvothermal synthesis. Then, antibacterial activity was evaluated against bacteria isolated from human saliva. Behavior and nanoparticle solutions were evaluated in human saliva and control (artificial saliva and deionized water). Results were statistically compared.

Results: The NP mixtures had an average size of $30 \pm 3 \mathrm{~nm}$, while the commercial Ag NPs had an average size of $55 \pm 5 \mathrm{~nm}$. The suspensions displayed differing antibacterial activities and kinetics of destabilisation processes, depending on NPs composition and fluid types.

Conclusion: The present study showed that all NPs suspensions displayed significant destabilisation and high destabilisation over the $24 \mathrm{~h}$ of the analyses. The agglomeration processes of NPs in human saliva can be reversible.
\end{abstract}

Keywords: nanomaterials, controlled drug release, nanoparticles, metal nanoparticles, bacteria

\section{Introduction}

Metallic and non-metallic biomaterials are widesNPread in contemporary regenerative medicine, and are used to help recreate missing tissues. As a favourable niche for bacterial settlement and biofilm formation, they carry an increased risk of bacterial and fungal infection, which may lead to severe complications and an increase in patient morbidity. This is most commonly seen in patients treated with partially external metallic biomaterials. The majority of these are used in the treatment of orofacial trauma, congenital or acquired morphologic diseases, tumours and much more. In most cases, peri-implant infections lead to local or general complications, such as non-unions, abscesses, osteomyelitis or even septicaemia and death. In general, empiric antibiotic therapy is commonly applied as an accompanying treatment procedure related to implant infection. However, due to the extreme resistance of the biofilm to drugs and the host's immune system, biomaterial-associated infections have significantly contributed to the global increase in bacterial resistance to widely used antibiotics over the past 30 years. ${ }^{1}$ Despite the efforts being made in treatment modalities, in most cases the infected material must be removed in order to decrease the risk of septicaemia and patient death. As orofacial infections are most
Correspondence: Agnieszka Mielczarek Department of Conservative Dentistry, Medical University of Warsaw,

Binieckiego 6, Warsaw 02-097, Poland

Tel +4822 II6 6446

Fax +48 5720154

Email sekretariat.zachowawcza@wum. edu.pl 
often inadequately treated by means of antibiotics, their overuse has contributed significantly to the global increase in multi drug resistant (MDR) species. As the 21st century has been called the "post-antibiotic era", new approaches are needed for infection prevention and treatment. In recent years, nanomaterials have entered the dental market as promising alternatives for their older counterparts, giving rise to a new field of science described as "nanodentistry". 2,3 This approach assumes two major breakthroughs. One is associated with an improvement in the biomechanical properties of the restoration materials, and the other in providing new solutions to the current limitations associated with implant-derived drug delivery. ${ }^{4}$ The release of NPs or their ions into the environment has been described as the most important factor contributing to broad antibacterial activity, increasing the longevity of the biomaterial within the tissues. There are some reports available on the antibacterial activity of nanoparticles against oral pathogens, but the results are extremely diversified. Confounding effects are often caused by significant discrepancies between the in vitro and in vivo environments. The oral cavity is a distinct ecosystem which significantly differs from all others in the human body. The presence of protein- and sugar-rich saliva and bacteria, which cover all surfaces in the mouth, exerts an important effect on drug pharmacokinetics and bioavailability. It was shown that nanoparticles released into the oral cavity may change their physicochemical properties by the formation of a protein corona (PC). Such fluctuations in the chemical composition of biomolecules may significantly contribute to the material's antibacterial activity and toxicity to human tissues as well. The potential for carcinogenic effects cannot be neglected. Moreover, it is known that bacteria can develop resistance to NPs as well, when they are applied incorrectly, especially in the oral cavity. ${ }^{5}$ Therefore, in order to fully comprehend the tasks associated with estimating the bio-safety of different NPs in clinical use, the phenomena influencing NPs activity in the specific biological environment must be evaluated in more detail. ${ }^{6,7}$ This process describes the changes in the physicochemical properties of the given NPs in certain biological fluids, determining NPs antimicrobial activity and toxicity in vivo, which may differ significantly from results obtained in vitro. ${ }^{3,8-11}$ There are several reports on the interaction of NPs with human blood serum, ${ }^{12}$ but studies investigating the behaviour of certain NPs in human saliva, their potential effect on the tissues of the oral cavity, their diffusion through the mucosa and their impact on vital organs remain in the initial phases. $^{13,14}$
In recent years, nano zinc oxide $(\mathrm{ZnO})$ and nanosilver (Ag) have attracted enormous interest in pharmacy and biomedicine thanks to their antibacterial properties. ${ }^{15,16}$ Due partly to its bleaching and matting properties, $\mathrm{ZnO}$ is used in the production of creams, dressings, powders, baby powders and specialist toothpastes. $\mathrm{ZnO}$ is a popular mineral UV filter used in cosmetics that offer sunlight protection. Research is being carried out on the application of $\mathrm{ZnO}$ nanostructures in biomedical imaging, drug delivery, gene delivery, biosensing and denture modification. ${ }^{17-22}$ Ag NPs, mainly thanks to their antibacterial action, ${ }^{5,23,24}$ are already applied in such products as dressings, toothpastes, cosmetics, materials intended for contact with food, textiles (e.g. socks) and shoes. ${ }^{25,26}$ In the case of Ag nanostructures, research is being conducted on a variety of applications, such as for the creation of novel antimicrobial coatings and agents, drugdelivery formulations, detection and diagnosis platforms, tissue restoration, regeneration materials and denture modification. $^{27-33}$

The aim of this study is to investigate new nano-formulations based on two of the most commonly applied dental materials: zinc oxide nanoparticles (ZnO NPs) and silver nanoparticles (Ag NPs), compounds used against clinical strains of oral gram-positive and gram-negative bacteria. Additionally, the evaluation of the release profiles and the formation of nanoparticle-protein-sugar complexes in the saliva and human serum will be a first step toward better understanding of NPs behaviour in a biological environment and how NP-protein complexes may contribute to potential cytotoxicity. The verification of the hypothesis should outline future directions in the field of dental nano-biomaterials and provide better insight into antibacterial approaches against nosocomial infections in regenerative medicine of the head and neck. Finally, it should provide important information on reliable ways to reduce the development of global bacterial resistance to the currently overused antibiotics, especially those used in odontogenic infections.

\section{Materials And Methods}

\section{Patient Selection And Saliva Sampling}

A total of 30 patients aged 18-53 years (15 males, 15 females), treated due to dental caries at the Department of Conservative Dentistry, Warsaw Medical University, were randomly selected for stimulated saliva sampling. This study was conducted in accordance with the Declaration of Helsinki. All the patients received and 
signed the patient informed consent, and the study was approved by the Warsaw Medical University Ethical Committee, ref no. KB/150/2018. The patients refrained from eating, drinking and using mouth-cleaning products $2 \mathrm{hrs}$ prior to saliva collection. Then the patients were asked to chew on a paraffin gum and deposit a total volume of $6 \mathrm{~mL}$ of saliva in three $2 \mathrm{~mL}$ Eppendorf tubes (Oral Swab Collection Kit, Salimetrics, USA). Then, after the collection, the samples were transported (Cryovial 2 Cryostorage Box, Salimetrics, USA) for further research to the Department of Antibiotics and Microbiology, National Medicines Institute, Warsaw, Poland $(2 \mathrm{~mL}$ sample from each patient) and the Laboratory of Nanostructures, Institute of High Pressure Physics (UNIPRESS), Polish Academy of Sciences (4 mL sample from each patient).

\section{Preparation Of Nanoparticles And Their Solutions, Methods \\ Substrates}

The following reagents were used: zinc acetate dihydrate $\left(\mathrm{Zn}\left(\mathrm{CH}_{3} \mathrm{COO}\right)_{2} \cdot 2 \mathrm{H}_{2} \mathrm{O}, \mathrm{Zn}(\mathrm{Ac})_{2} \cdot 2 \mathrm{H}_{2} \mathrm{O}\right.$ analytically pure, Chempur, Poland); silver acetate anhydrous (Ag $\left(\mathrm{CH}_{3} \mathrm{COO}\right), \mathrm{Ag}(\mathrm{Ac})$, analytically pure, Chempur, Poland); ethylene glycol (EG, ethane-1,2-diol, $\mathrm{C}_{2} \mathrm{H}_{4}(\mathrm{OH})_{2}$, pure, Chempur, Poland); Ag-NPs (Hydro Silver 1000 (55 \pm 5 nm, PVA coating, water suspensions, 1000 ppm), Amepox, Łódź, Poland) $;^{34}$ deionized water $\left(\mathrm{H}_{2} \mathrm{O}\right)$ (specific conductance below $0.1 \mu \mathrm{S} / \mathrm{cm}$, HLP 20UV, Hydrolab, Poland); artificial saliva for medical and dental research (Pickering Laboratories, Inc., Mountain View, California, USA). The reagents were not purified and were used "as received".

\section{Synthesis Of $\mathrm{ZnO} N P s$ And $\mathrm{ZnO}+x \cdot \mathrm{Ag}$ NPs}

$\mathrm{ZnO}$ NPs were obtained by the microwave solvothermal synthesis (MSS) in accordance with the procedure we established ${ }^{35-38}$ while $\mathrm{ZnO}+\mathrm{x} \cdot \mathrm{Ag}$ NPs were created for the first time with the use of MSS. The composition of the precursors determined by equation $(1)^{38}$ is summarized in Table 1.

$$
x_{A g^{+}}=\frac{n_{A g^{+}}}{n_{A g^{+}}+n_{Z n^{2+}}}
$$

The mixture of the acetates in EG $(300 \mathrm{~mL})$ was stirred $(450 \mathrm{rpm})$ at a temperature of $70^{\circ} \mathrm{C}$ using hot-plate magnetic stirrers (SLR, SI Analytics, Germany) until complete dissolution. Subsequently, each obtained precursor solution was poured into a bottle $(500 \mathrm{~mL}, \mathrm{PP})$ and sealed. Once the solutions achieved ambient temperature, their
Table I Composition Of Precursors Of Synthesis Of ZnO NPs And $\mathrm{ZnO}+x \cdot \mathrm{Ag}$ NPs

\begin{tabular}{|l|l|l|}
\hline Name & $\mathbf{C m}_{\mathrm{Zn}(\mathbf{A c}) \mathbf{2} \cdot \mathbf{2 H} 2 \mathbf{O}\left(\mathbf{m o l} / \mathbf{d m}^{\mathbf{3}}\right)}$ & $\begin{array}{l}\mathbf{C m}_{\mathbf{A g}(\mathbf{A c}) \mathbf{2}} \\
\left(\mathbf{m o l} / \mathbf{d m}^{\mathbf{3}}\right)\end{array}$ \\
\hline $\mathrm{ZnO}$ & 0.30373 & 0 \\
$\mathrm{ZnO}+0.1 \% A g$ & 0.30373 & 0.00030 \\
$\mathrm{ZnO}+1 \% \mathrm{Ag}$ & 0.30373 & 0.00307 \\
$\mathrm{ZnO}+10 \% A g$ & 0.30373 & 0.03375 \\
\hline
\end{tabular}

Abbreviations: $\mathrm{ZnO}$, zinc oxide; $\mathrm{Ag}$, silver; $\mathrm{NPs}$, nanoparticles; $\mathrm{Cm}$, molar concentration; dm, decimetre; $\mathrm{Zn}(\mathrm{Ac})_{2} \cdot 2 \mathrm{H}_{2} \mathrm{O}$, zinc acetate dehydrate; $\mathrm{Zn}(\mathrm{Ac})_{2} \cdot 2 \mathrm{H}_{2} \mathrm{O}$, silver acetate anhydrous.

initial $\mathrm{H}_{2} \mathrm{O}$ content was determined. Later, calculated quantities of $\mathrm{H}_{2} \mathrm{O}$ were added to the solutions so that the final concentration of $2 \mathrm{wt} \%$ could be achieved in each precursor solution, which was confirmed by analysis.

The syntheses were performed in a microwave reactor, model MSS2 ("cup" chambers, $400 \mathrm{~mL}, 3 \mathrm{~kW}, 2.45 \mathrm{GHz}$, IHPP PAS, ITeE-PIB, ERTEC-Poland). ${ }^{39,40}$ The synthesis parameters were as follows: feedstock volume $270 \mathrm{~mL}$, reaction duration $12 \mathrm{mins}$, microwave power $1 \mathrm{~kW}$. The obtained suspensions were centrifuged (MPW-350, MPW Med Instruments, Poland) in order to separate the solid synthesis product from the EG The sediments were rinsed three times with deionized water and subsequently $\mathrm{H}_{2} \mathrm{O}$ was added to the sediments, characterized by a paste consistency and stirred intensively to obtain suspensions. 40 $\mathrm{mL}$ of the suspension was collected from each sample, frozen using liquid nitrogen and dried in a freeze dryer (Lyovac GT-2, SRK Systemtechnik GmbH, Germany).

\section{Characterization Of NPs}

The full description of the measurement procedures used is included in the publication. ${ }^{36}$ The concentration by weight of the water in the precursor solutions was determined using the coulometric titration technique, based on the assumptions of the Karl Fischer method (Cou-Lo AquaMAX KF, GR Scientific, United Kingdom).

The phase composition of the NPs samples was determined by the X-ray diffraction method (XRD) (X'Pert PRO, copper lamp $(\mathrm{CuK} \alpha)$, Panalytical, Netherlands). The diffraction analyses were performed in $0.02^{\circ}$ steps within the range of the 2-theta angle, from $10^{\circ}$ to $100^{\circ}$, at room temperature. Scherrer's formula was used to determine the average crystallite size. ${ }^{35}$ Thanks to the analysis of the diffraction peak profile by the FW15/45M method, ${ }^{41}$ which was used in the Nanopowder XRD Processor Demo web application, the average crystallite $\operatorname{size},{ }^{42,43}$ the 
deviation of the average crystallite size and the crystallite size distribution were determined.

The NPs samples for the density and specific surface area tests were desorbed in a VacPrep 061 (Micromeritics $^{\circledR}$ ) degassing station for $2 \mathrm{~h}\left(0.05 \mathrm{mbar}, 150^{\circ} \mathrm{C}\right)$. The skeleton density (pycnometric density) was determined using a helium pycnometer $\left(24 \pm 1^{\circ} \mathrm{C}\right.$, ISO 12154:2014, AccuPyc II 1340, FoamPyc V1.06, Micromeritics ${ }^{\circledR}$, USA). The specific surface area was determined by the nitrogen $\left(99.999 \% \mathrm{~N}_{2}\right)$ adsorption method based on the linear form of the BET (BrunauerEmmett-Teller) isotherm equation (ISO 9277:2010, Gemini 2360, V 2.01, Micromeritics ${ }^{\circledR}$, USA). The average size of the NPs was calculated based on the obtained results of density and specific surface area, assuming that the samples contained only identical spherical particles. ${ }^{35}$

The morphology of the NPs was tested using a scanning electron microscope (SEM) ULTRA PLUS (ZEISS, Germany). The quantitative $\mathrm{X}$-ray microanalysis of the zinc and silver content of the pressed samples (pastilles with a $5 \mathrm{~mm}$ diameter) was performed by the energy-dispersive spectrometry (EDS) method using an X-ray spectrometer (Quantax 400, Bruker, USA). The results of the quantitative analysis of zinc and silver presented here are the averaged values from 5 analyses.

A Bruker Tensor 27 infrared spectrometer, equipped with an Attenuated Total Reflectance (ATR, model: Platinum ATREinheit A 255), was used for the Fourier transform infrared (FT-IR) spectroscopy analysis (50 scans, range of $400-4000 \mathrm{~cm}^{-1}$, resolution of $4 \mathrm{~cm}^{-1}$, room temperature).

The samples of 5 NPs suspensions, each of $100 \mathrm{~mL}$ and concentration of $1000 \mathrm{ppm}$ before DLS measurement, were subjected to the ultrasonic homogenization process (UP200, Hielscher, Teltow, Germany) with the following parameters: duration 3 mins, amplitude 0.7 , cycle 1 , sonotrode diameter $14 \mathrm{~mm}$, without temperature stabilization. The homogenized suspensions, having achieved a room temperature of $22.9^{\circ} \mathrm{C}$, were added in appropriate quantities to $\mathrm{H}_{2} \mathrm{O}$, artificial saliva or human saliva to obtain the final concentration of $200 \mathrm{ppm}$.

\section{Microbiological Studies Collection Of Oral Bacteria And Preparation For The Studies}

The antimicrobial activity of the synthesised NPs was evaluated by the standardised pharmaceutical methods of drug testing commonly performed at the National Medicines Institute, Warsaw, Poland (accredited OMCL) against clinical isolates and standard strains of the bacteria and fungi isolated from the sampled saliva. The tests were performed according to the modified method recommended by the Clinical and Laboratory Standards Institute (CLSI), such as the M100 Performance Standards for Antimicrobial Susceptibility Testing, M02 Performance Standards for Antimicrobial Disk Susceptibility Tests and M07 Methods for Dilution Antimicrobial Susceptibility Tests for Bacteria That Grow Aerobically, commonly used in the determination of antimicrobial susceptibility.

Clinical isolates of Streptococcus Salivarius; S. oralis; S. mutans; S. mitis and Porphyromonas gingivalis; were sub-cultured, divided and grouped. S. salivarius, S. oralis, $S$. mutans and $S$. mitis were prepared using an overnight culture in Tryptic Soy Broth (TSB; Biomerieux), supplemented with a $10 \%$ yeast extract (Roth, Karlsruhe, Germany) under aerobic conditions at $37^{\circ} \mathrm{C}$ for $24 \mathrm{~h}$. Porphyromonas gingivalis were prepared by culturing for $48 \mathrm{~h}$ on a brain heart infusion medium (BHl; Oxoid, Wesel, Germany), supplemented with $10 \mu \mathrm{g} / \mathrm{mL}$ of vitamin $\mathrm{K}$ (Roth, Karlsruhe, Germany) under anaerobic conditions $\left(80 \% \mathrm{~N}_{2}, 10 \% \mathrm{H}_{2}, 10 \% \mathrm{CO}_{2}\right)$ at $37^{\circ} \mathrm{C}$ for $48 \mathrm{~h}$.

\section{Antibacterial Activity Of Nanoparticles Against Oral Cavity Bacteria}

In order to evaluate the antimicrobial activity of the nanoparticles and nanomaterials, minimum inhibitory concentration (MIC) values were measured by means of broth micro-dilution tests in 96-well microtiter plates. S. salivarius, $S$. oralis, $S$. mutans and $S$. mitis were cultured in the presence of the NPs at respective concentrations (Table 1) in BHI broth under aerobic conditions at $37^{\circ} \mathrm{C}$ for $24 \mathrm{~h}$. P. gingivalis was cultured in the presence of NPs in CDM supplemented with $10 \%$ human serum under anaerobic conditions $\left(80 \% \mathrm{~N}_{2}, 10 \% \mathrm{H}_{2}, 10 \%\right.$ $\mathrm{CO}_{2}$ ) at $37^{\circ} \mathrm{C}$ for $72 \mathrm{~h}$. Each test was performed in triplicate. The results were statistically analysed using Pearson's Chi square tests (STATISTICA12 PL). A P value of 0.05 was considered statistically significant for all tests.

\section{Behaviour Of Nanoparticles And Their Solutions In Human Saliva}

The average $\mathrm{ZnO}$ particle size was measured by the dynamic light scattering (DLS) method ( $\lambda=633 \mathrm{~nm}$, Zetasizer Nano-ZS ZEN 3600, Malvern Instruments Ltd., UK). The DLS measuring system with the automatic sample collection function comprised the following components: DLS analyser, titrator with magnetic stirrer and peristaltic pump, container for NPs suspensions, silicone hoses for supplying and discharging the suspension and a folded capillary cell (DTS1060 cuvette). The 
tests were carried out with the following parameters: $24^{\circ} \mathrm{C}$ temperature and $173^{\circ}$ measurement angle (backscattering), analysis model: auto mode, 6 measurements. A fresh portion of the sample was pumped once every hour to a DTS1060 measurement cuvette by the titrator (MPT-2, ZEN1001, Malvern Instruments Ltd., UK) for $24 \mathrm{~h}$. It must be underlined that the suspension sample was stirred using the magnetic stirrer in the MPT-2 titrator for the whole test duration. Zetasizer 7.11 software was used (Malvern Instruments Ltd).

The zeta potentials $(\zeta)$ of the samples were measured using a laser Doppler electrophoresis (LDE) analyser $(\lambda=633 \mathrm{~nm}$, Zetasizer Nano ZS ZEN3600, Malvern Instruments Ltd). The tests were performed in DTS1060 cuvettes with the following parameters: $24^{\circ} \mathrm{C}$ temperature, analysis model: auto mode, 6 measurements.

The $\mathrm{pH}$ measurement at room temperature $\left(23.2^{\circ} \mathrm{C}\right)$ was performed using an ERH-12-6 electrode (Hydromet, Gliwice, Poland) installed in the MPT-2 titrator. Three buffer solutions (Chempur, Piekary Slaskie, Poland) with a $\mathrm{pH}$ of $4 \pm 0.05,7$ \pm 0.05 and $9 \pm 0.05$ were used for calibrating the $\mathrm{pH}$ electrode.

The specific conductivity $(\sigma)$ measurement at room temperature $\left(23.2^{\circ} \mathrm{C}\right)$ was performed using an InLab 731 ISM conductivity probe (Mettler-Toledo, Greifensee, Switzerland) installed in a S400 Seven Excellence instrument (Mettler-Toledo, Greifensee, Switzerland). A conductivity standard (1413 $\mu \mathrm{S}$, Mettler-Toledo, Greifensee, Switzerland) was used to calibrate the conductivity probe.

The stability measurement was carried out by the static multiple light scattering (S-MLS) method, ${ }^{44,45}$ applied in a Turbiscan LAB analyser ( $\lambda=880 \mathrm{~nm}$, Formulaction, Toulouse, France). The samples were analysed in a sealed cylindrical glass bottle ( $4 \mathrm{~mL}, 14.7 \mathrm{~mm}$ outer diameter). The measurements were performed over $24 \mathrm{~h}$ hours at a temperature of $27^{\circ}$ C. Based on the data gathered by the Turbiscan LAB analyser, the Turbiscan Stability Index (TSI) was calculated, ${ }^{46,47}$ which is a unique parameter established for the comparison and characteristics of physical stability of various suspensions. ${ }^{48,49}$

The results were statistically analysed using One Way Anova (STATISTICA12 PL). A P value of 0.05 was considered statistically significant for all tests.

\section{Results}

\section{Characteristics Of NPs}

The results of the XRD tests (Figure 1) for the ZnO NPs sample revealed the presence of only one crystalline phase, where all the diffraction peaks were attributed to the hexagonal phase of $\mathrm{ZnO}$ (JCPDS No. 36-1451). The results of the XRD tests (Figure 1) for all samples with the addition of silver indicated the presence of two crystalline phases, namely the hexagonal phase of $\mathrm{ZnO}$ (JCPDS No. 36-1451) and the cubic phase of Ag (JCPDS No. 04-0783). The diffraction pattern showed an increase in intensity of certain diffraction peaks in line with the increase in the Ag content in the samples, which confirmed that the synthesis method we developed leads to the formation of two different products. The obtained XRD results proved that the $\mathrm{Ag}^{+}$ions were not incorporated into the crystalline lattice of $\mathrm{ZnO}$, but during the synthesis were reduced to metallic $\mathrm{Ag}^{\circ}$ and the obtained product of the microwave solvothermal synthesis was a mixture of $\mathrm{ZnO}$ NPs with Ag NPs.

Figure 2 shows representative SEM images of the obtained samples. The powders of the nanoparticles of $\mathrm{ZnO}, \mathrm{ZnO}+0.1 \% \mathrm{Ag}$ and $\mathrm{ZnO}+1 \% \mathrm{Ag}$ were composed of homogeneous particles with a spherical shape, while a small quantity of particles with an elliptical shape were observed in the SEM images (Figure 2B, D and F). The $\mathrm{ZnO}+10 \% \mathrm{Ag}$ sample shown in Figure $2 \mathrm{G}$ was composed mainly of compact structures, whose shape resembled a "cauliflower" structure. The size of the NPs for all samples ranged from $20-30 \mathrm{~nm}$ to $60-90 \mathrm{~nm}$.

Figure 3 shows SEM photographs taken using the angle-sensitive backscatter (AsB) detector, thanks to which the agglomerates/aggregates of Ag NPs could be discerned among the nanoparticle mixture. In order to confirm that the white fields visible in the SEM photographs (Figure 3) were agglomerates/aggregates of $\mathrm{Ag}$ NPs, mapping of the elements was carried out using the EDS method.

The most important results of the characterization of the obtained NPs samples are summarized in Table 2. The difference between the theoretical density of $\mathrm{Ag}$ $\left(10.50 \mathrm{~g} / \mathrm{cm}^{3}\right)^{50}$ and the theoretical density of $\mathrm{ZnO}(5.61$ $\left.\mathrm{g} / \mathrm{cm}^{3}\right)^{51}$ explains the increase in density of the samples from 5.31 to $5.82 \mathrm{~g} / \mathrm{cm}^{3}$ in line with the increase in the silver content from $0 \% \mathrm{~mol}$ to $10 \% \mathrm{~mol}$. The specific surface area first increased from $34.6 \mathrm{~m}^{2} / \mathrm{g}$ to $37.7 \mathrm{~m}^{2} / \mathrm{g}$ in line with the increase in the Ag content from $0 \%$ mol to $0.1 \% \mathrm{~mol}$, and subsequently decreased to $31.4 \mathrm{~m}^{2} / \mathrm{g}$ in line with the increase in the $\mathrm{Ag}$ content to $10 \% \mathrm{~mol}$. The change in the specific surface area trend was probably caused by the formation of a greater quantity of aggregates of Ag NPs in line with the increase in the Ag content in the samples. The tendency of unmodified Ag NPs for rapid agglomeration/aggregation is widely known. While 


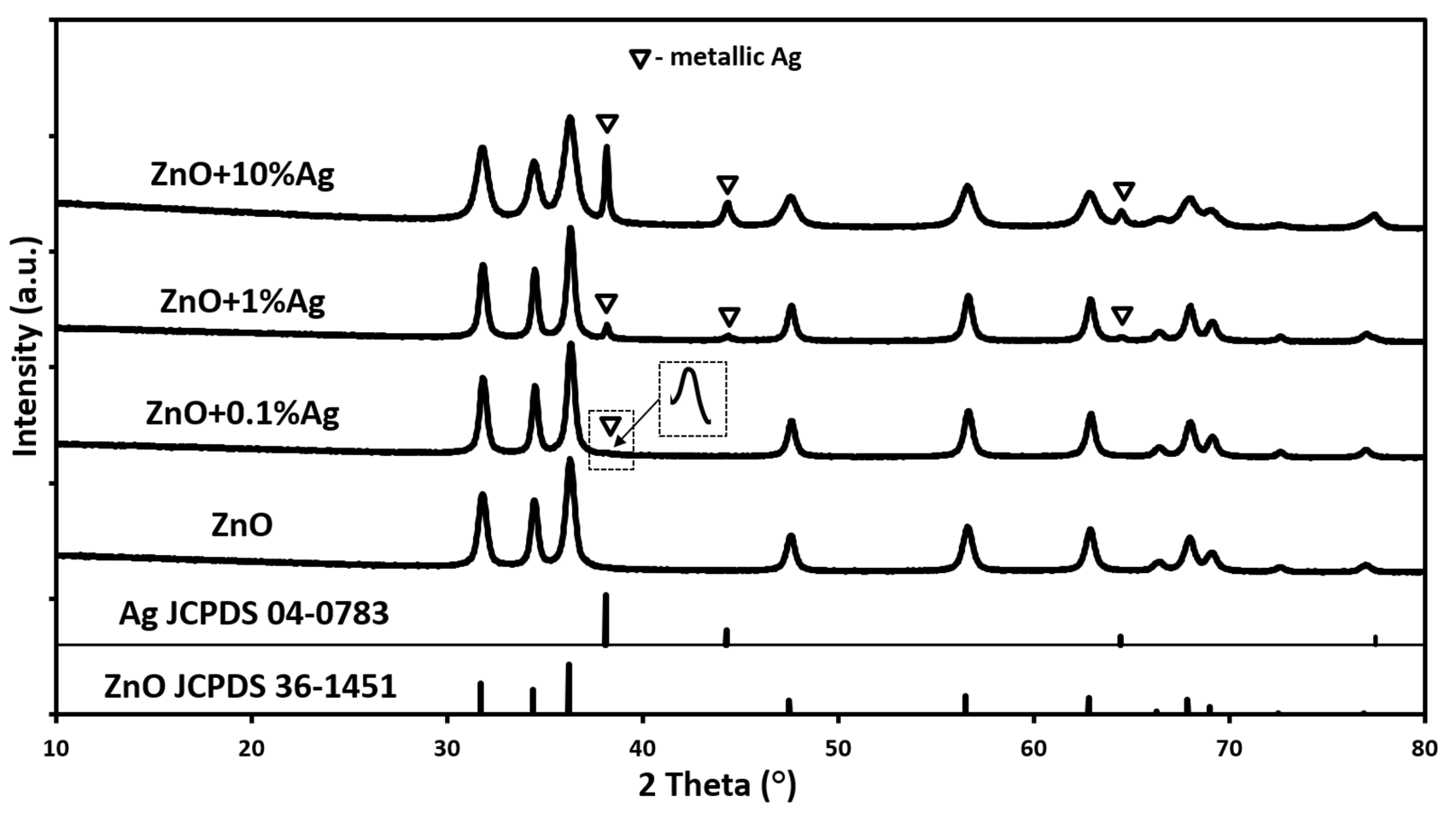

Figure I X-ray diffraction patterns of $\mathrm{ZnO} N P s$ and $\mathrm{ZnO}+\mathrm{x} \cdot \mathrm{Ag} \mathrm{NPs}$.

Abbreviations: $\mathrm{ZnO}$, zinc oxide; Ag, silver; NPs, nanoparticles; JCPDS, Joint Committee on Powder Diffraction Standards; a.u., arbitrary unit.

preparing the samples, no surfactants were used for modifying the surface of the NPs, which would prevent the agglomeration or aggregation process. ${ }^{52}$

The average particle size calculated based on the conversion of the density and specific surface area results for all synthesized samples ranged from 30 to $33 \mathrm{~nm}$. The average crystallite size, in turn, calculated using the Nanopowder XRD Processor Demo application for all samples ranged from 28 to $29 \mathrm{~nm}$. It must be emphasised that the average $\mathrm{ZnO}$ crystallite size calculated based on Scherrer's formula for the samples with an $\mathrm{Ag}$ content from $0 \%$ to $1 \%$ was $30-31 \mathrm{~nm}$, while for the $\mathrm{ZnO}+10 \%$ $\mathrm{Ag}$ sample merely $16 \mathrm{~nm}$. The difference in the size of the obtained $\mathrm{ZnO}$ crystallites in the $\mathrm{ZnO}+10 \% \mathrm{Ag}$ was caused by the simultaneous synthesis of ZnO NPs and Ag NPs, which, given the $10 \%$ silver acetate content relative to the zinc acetate, contributed to the change in the course of $\mathrm{ZnO}$ NPs growth. ${ }^{36}$ The calculated size of the $\mathrm{Ag}$
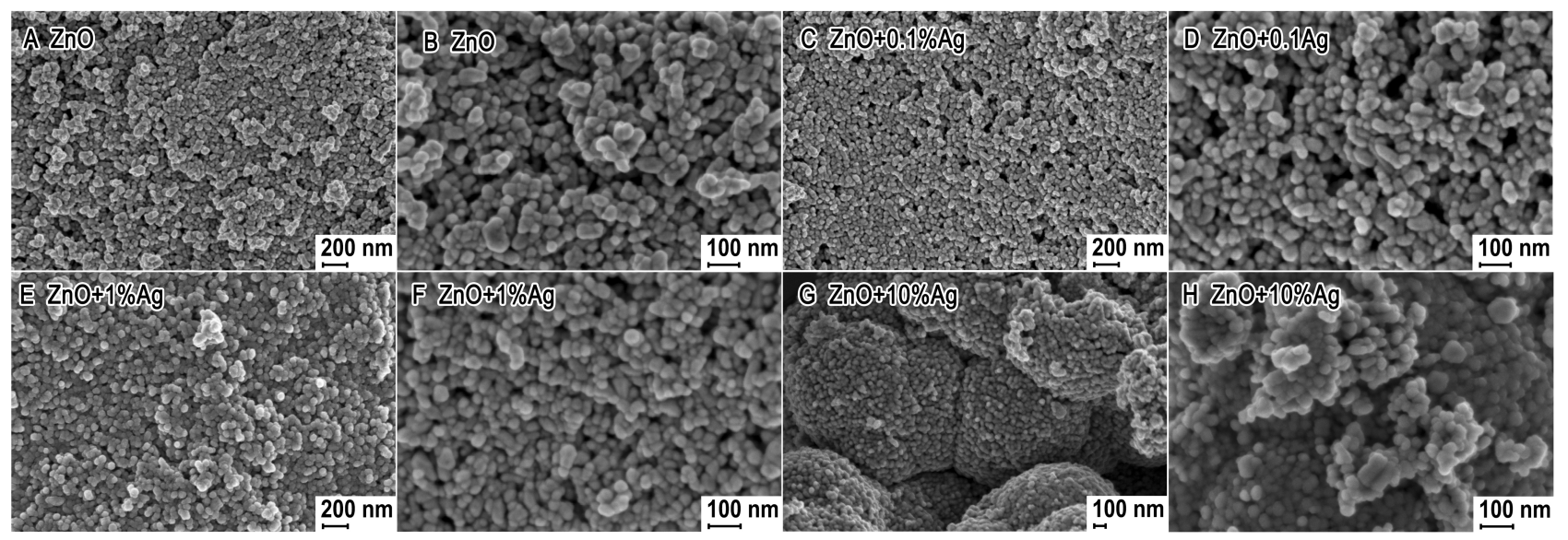

Figure 2 SEM photographs of $\mathrm{ZnO}+x \cdot \mathrm{Ag}$ with varying silver content: $(\mathbf{A})$ and $(\mathbf{B}) 0 \% \mathrm{Ag} ;(\mathbf{C})$ and $(\mathbf{D}) 0.1 \% \mathrm{Ag} ;(\mathbf{E})$ and $(\mathbf{F}) \quad 1 \% \mathrm{Ag} ;(\mathbf{G})$ and $(\mathbf{H}) 10 \% \mathrm{Ag}$. Abbreviations: SEM, scanning electron microscope; $\mathrm{ZnO}$, zinc oxide; $\mathrm{Ag}$, silver. 


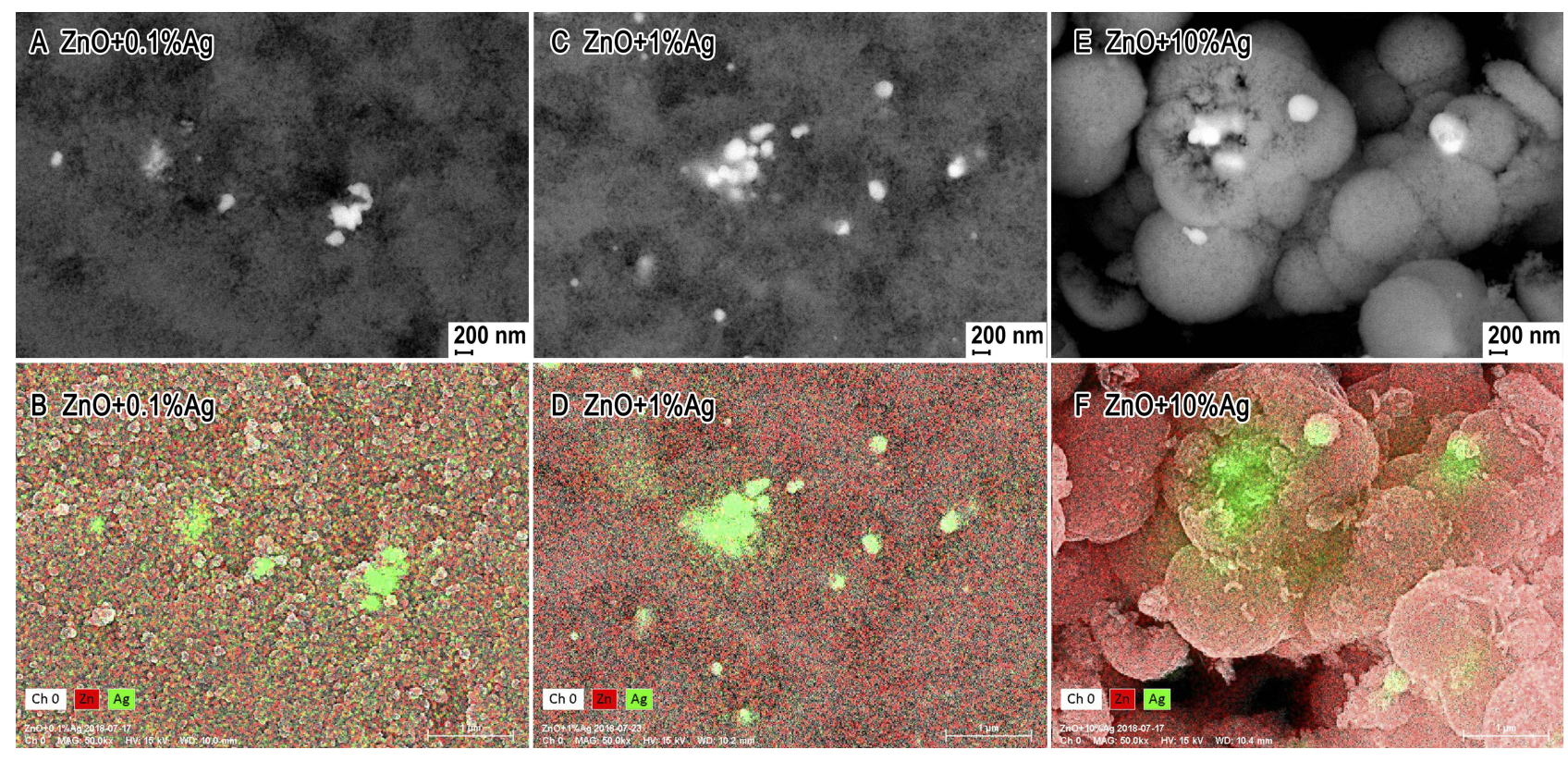

Figure 3 SEM photographs taken using the Angle-sensitive Backscatter (AsB) detector: (A) and (B) ZnO; (C) and (D) $\mathrm{ZnO}+0.1 \% A g ;(\mathbf{E})$ and $(\mathbf{F}) \mathrm{ZnO}+1 \% \mathrm{Ag}$; (G) and (H) $\mathrm{ZnO}+10 \% \mathrm{Ag}$. EDS mapping of $\mathrm{Zn}$ and $\mathrm{Ag}$ elements: (A) and (B) $\mathrm{ZnO}+0.1 \% \mathrm{Ag}$; (C) and (D) $\mathrm{ZnO}+1 \% \mathrm{Ag}$; (E) and (F) $\mathrm{ZnO}+10 \% \mathrm{Ag}$.

Abbreviations: SEM, scanning electron microscope; AsB, Angle-sensitive Backscatter; ZnO, zinc oxide; Ag, silver; EDS, Energy Dispersive X-Ray Spectroscopy.

crystallites was $35 \mathrm{~nm}$ and $39 \mathrm{~nm}$ for the $\mathrm{ZnO}+1 \% \mathrm{Ag}$ and $\mathrm{ZnO}+10 \% \mathrm{Ag}$ samples, respectively. For the $\mathrm{ZnO}+0.1 \% \mathrm{Ag}$ sample, it was impossible to calculate the crystallite size due to the low intensity of the diffraction peaks. A virtually identical crystallite size distribution was obtained for three samples, which ranged from $\approx 7 \mathrm{~nm}$ to $\approx 70 \mathrm{~nm}$ (Figure $4 \mathrm{~A}-\mathrm{C}$ ), while for the $\mathrm{ZnO}+10 \% \mathrm{Ag}$ sample the distribution ranged from $\approx 2 \mathrm{~nm}$ to $\approx 85 \mathrm{~nm}$ (Figure 4D).

The actual chemical composition of the samples is summarised in Table 3. While calculating the nominal silver content, we assumed that the $\mathrm{Ag}^{+}$ions would constitute an admixture in the crystalline lattice of $\mathrm{ZnO}$ and ignored the oxygen share in the calculations. As indicated by the XRD and SEM analyses, the obtained synthesis product was a mixture of $\mathrm{ZnO}$ NPs and Ag NPs, and therefore the actual Ag content was lower than the nominal one. We used nominal silver contents for the purposes of naming the samples in the whole paper.

\section{Antibacterial Activity}

Among all the tested nanoparticles and their compounds, Ag NPs (hydrosilver) was the most efficient, providing MICs against all tested bacteria, even at a concentration of $1 \mathrm{ppm}(p=0.000)$. The minimum inhibitory concentrations for ZnO NPs were $125 \mathrm{ppm}$ against all oral streptococci, with no significant differences between the species, and ranged from 125 to 250

Table 2 Characteristics Of NPs

\begin{tabular}{|c|c|c|c|c|c|}
\hline Sample & $\begin{array}{l}\text { Specific Surface } \\
\text { Area, } a_{s} \pm \sigma\left(\mathrm{m}^{2} / g\right)\end{array}$ & $\begin{array}{l}\text { Skeleton } \\
\text { Density, } \rho_{\mathrm{s}} \pm \sigma \\
\left(\mathrm{g} / \mathrm{cm}^{3}\right)\end{array}$ & $\begin{array}{l}\text { Average Particle } \\
\text { Size From SSA } \\
\text { BET, d } \pm \sigma(\mathrm{nm})\end{array}$ & $\begin{array}{l}\text { Average Crystallite Size } \\
\text { From Nanopowder XRD } \\
\text { Processor Demo, } d \pm \sigma(\mathrm{nm})\end{array}$ & $\begin{array}{l}\text { Average Crystallite Size, } \\
\text { Scherrer's formula, } \\
(\mathrm{nm})\end{array}$ \\
\hline $\mathrm{ZnO}$ & 34.6 & $5.3 I \pm 0.02$ & $33 \pm 1$ & $29 \pm 9$ & $31 \pm 4$ \\
\hline $\mathrm{ZnO}+0.1 \% \mathrm{Ag}$ & 37.7 & $5.34 \pm 0.02$ & $30 \pm 1$ & $28 \pm 9$ & $30 \pm 4$ \\
\hline $\mathrm{ZnO}+1 \% \mathrm{Ag}$ & 33.9 & $5.37 \pm 0.02$ & $33 \pm 1$ & $29 \pm 9$ & $\begin{array}{l}31 \pm 4(\mathrm{ZnO}) \\
35 \pm 15(\mathrm{Ag})\end{array}$ \\
\hline $\mathrm{ZnO}+10 \% \mathrm{Ag}$ & 31.4 & $5.82 \pm 0.03$ & $33 \pm 1$ & $28 \pm 16$ & $\begin{array}{l}16 \pm 1(\mathrm{ZnO}) \\
39 \pm 15(\mathrm{Ag})\end{array}$ \\
\hline
\end{tabular}

Abbreviations: $\mathrm{ZnO}$, zinc oxide; Ag, silver; NPs, nanoparticles; $a_{s}$, specific surface area; $\rho_{s}$, skeleton density; SSA, Specific surface area; BET, Brunauer Emmett Teller; $d$, diameter; $\sigma$, standard deviation; g, gram; $\mathrm{cm}$, centimetre; $\mathrm{nm}$, nanometer. 


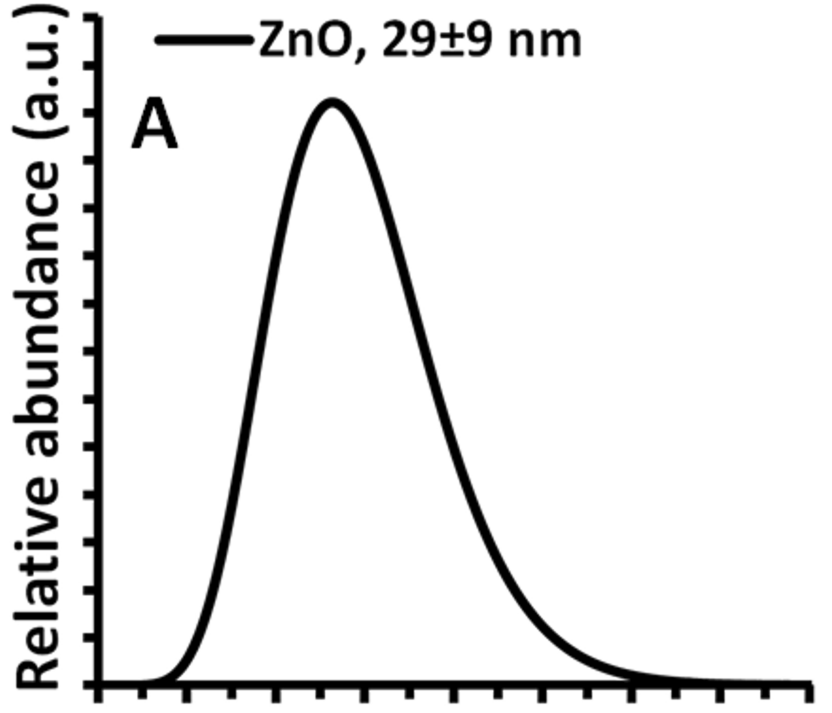

$\begin{array}{lllllllll}0 & 10 & 20 & 30 & 40 & 50 & 60 & 70 & 80\end{array}$ Size of crystallite $(\mathrm{nm})$

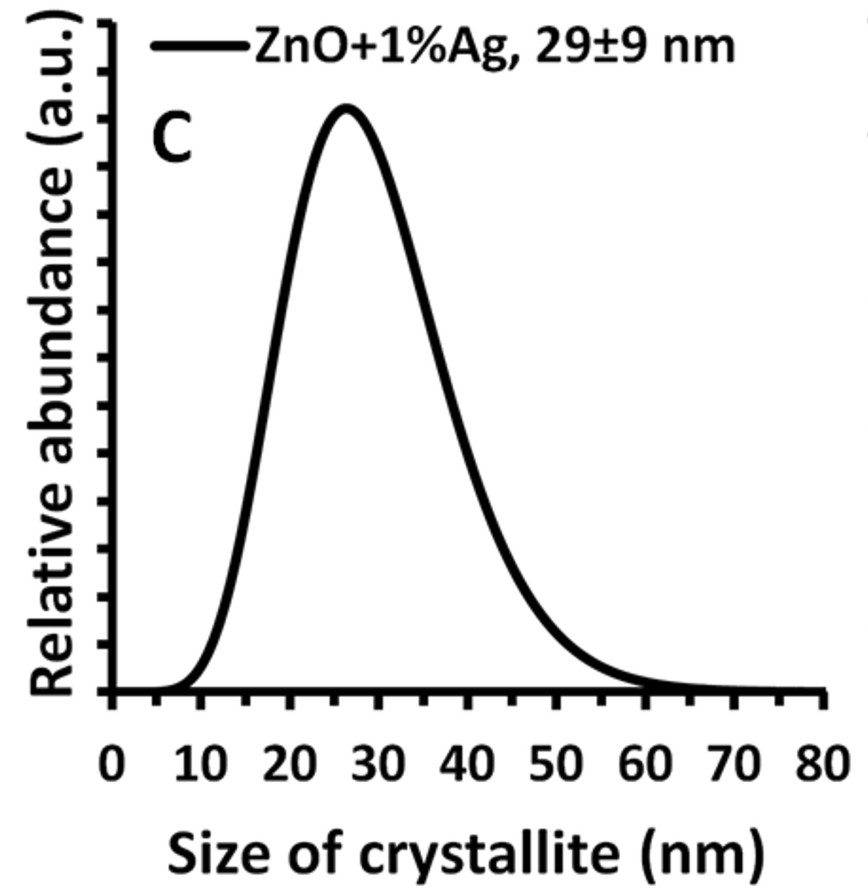

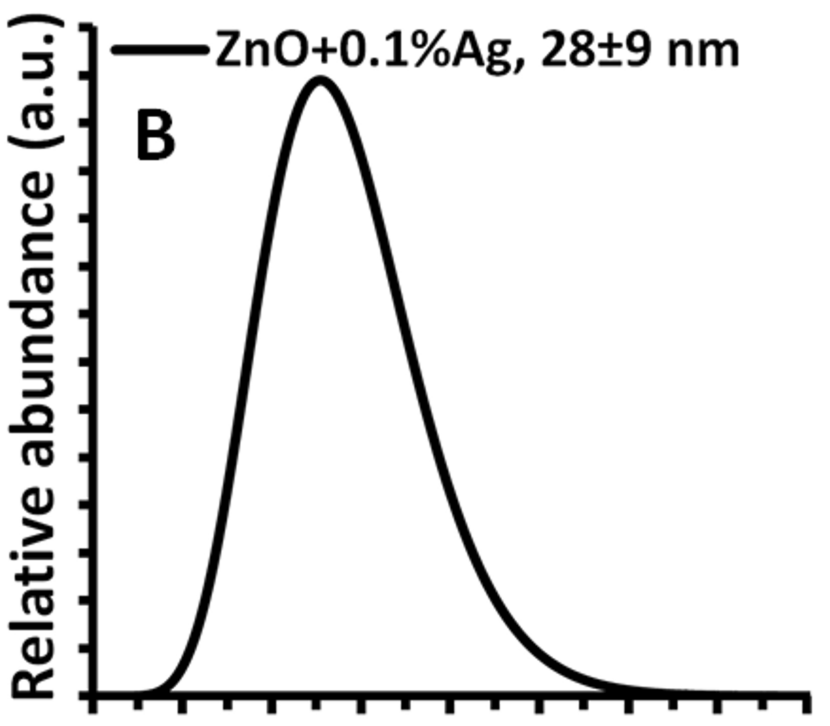

$\begin{array}{lllllllll}0 & 10 & 20 & 30 & 40 & 50 & 60 & 70 & 80\end{array}$ Size of crystallite $(\mathrm{nm})$

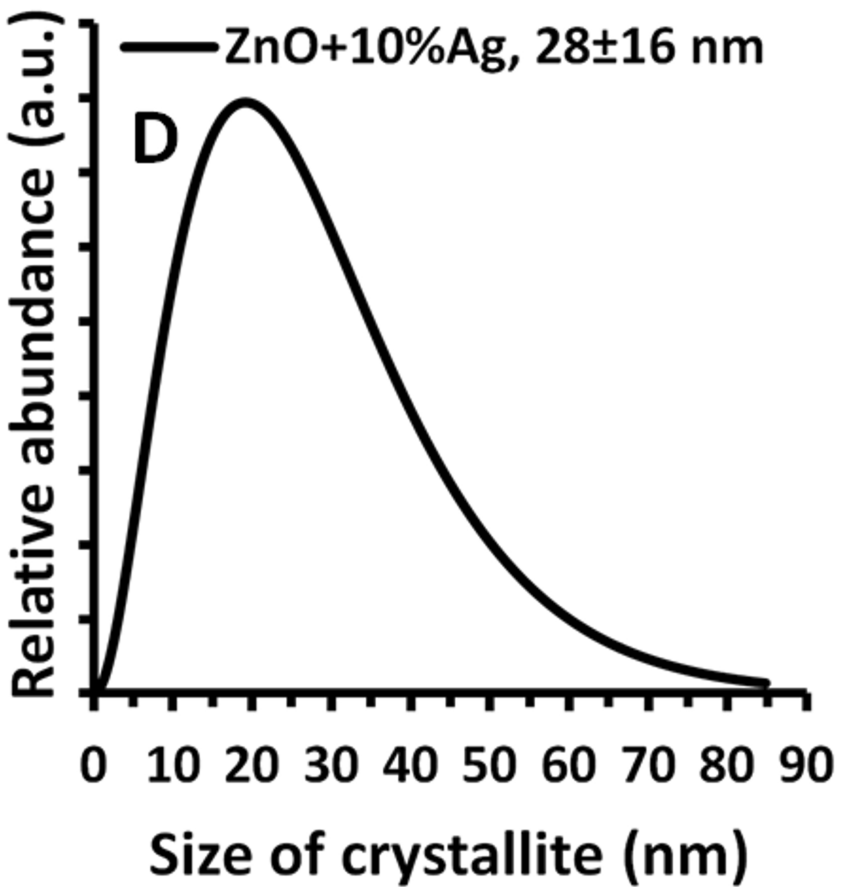

Figure 4 Crystallite size distribution obtained using Nanopowder XRD Processor Demo, pre.d.ver.0.0.8, () Pielaszek Research. ${ }^{38,41}$

Abbreviations: $\mathrm{XRD}, \mathrm{X}$-ray diffraction; $\mathrm{ZnO}$, zinc oxide; $\mathrm{Ag}$, silver; a.u., arbitrary unit; $\mathrm{nm}$, nanometer.

ppm against anaerobic species without significant differences between species (Figure 5). For the $\mathrm{ZnO}$ $+0.1 \% \mathrm{Ag}, \mathrm{ZnO}+1 \% \mathrm{Ag}$ and $\mathrm{ZnO}+10 \% \mathrm{Ag}$ samples, antibacterial concentrations providing MICs ranged from 32 to $64 \mathrm{ppm}$ against all the tested bacteria, regardless of silver percentage. However, regardless of silver percentage, the antibacterial potential of zinc oxide NPs increased significantly. The antibacterial susceptibility to certain NPs was comparable between bacterial species. Only 5C species were significantly more susceptible to the NPs tested among all oral bacterial species (Supplementary materials). 
Table 3 Results Of The Chemical Composition Of NP Samples By The EDS Method

\begin{tabular}{|l|l|l|l|l|}
\hline \multirow{2}{*}{ Sample } & \multicolumn{2}{|l|}{ Actual Content Of Silver, Atom \% } & \multirow{2}{*}{ Actual Stoichiometry } \\
\cline { 2 - 5 } & Zinc & Oxygen & Silver & \\
\hline $\mathrm{ZnO}$ & 51.057 & 48.943 & 0 & $\mathrm{Zn}, \mathrm{O}_{0.96}$ \\
$\mathrm{ZnO}+0.1 \% \mathrm{Ag}$ & 50.460 & 49.497 & 0.042 & $\mathrm{Zn}, \mathrm{O}_{0.981}+0.00042 \mathrm{Ag}$ \\
$\mathrm{ZnO}+1 \% \mathrm{Ag}$ & 51.260 & 48.224 & 0.516 & $\mathrm{Zn}, \mathrm{O}_{0.940}+0.00516 \mathrm{Ag}$ \\
$\mathrm{ZnO}+10 \% \mathrm{Ag}$ & 44.490 & 51.050 & 4.46 & $\mathrm{Zn}, \mathrm{O}_{1.147}+0.0446 \mathrm{Ag}$ \\
\hline
\end{tabular}

Abbreviations: ZnO, zinc oxide; Ag, silver; \%, percentages; NP, nanoparticle; EDS, Energy Dispersive X-Ray Spectroscopy.

\section{Nanoparticles And The Biological Fluids}

Table 4 summarises the analysis results of the NP suspensions, performed once they were obtained $(\mathrm{t}=0 \mathrm{~h})$. For the $\mathrm{ZnO}, \mathrm{ZnO}+0.1 \% \mathrm{Ag}$ and $\mathrm{ZnO}+1 \% \mathrm{Ag}$ samples, very similar results for average particle size were obtained, ranging from $114 \mathrm{~nm}$ to $145 \mathrm{~nm}$. The average agglomerate size for the $\mathrm{ZnO}$ $+10 \% \mathrm{Ag}$ sample was $667 \mathrm{~nm}$, while for the Ag NPs sample it was $239 \mathrm{~nm}$. After adding the NPs to the artificial saliva, a considerable and rapid growth of agglomerates occurred in all the obtained samples. The impact of the Ag NP content in the suspensions on the average size of the obtained NP agglomerates was visible, i.e. the higher the Ag NP content in the $\mathrm{ZnO}+\mathrm{x} \cdot \mathrm{Ag}$ suspension, the larger the agglomerates obtained (Table 4). The average agglomerate size for the Ag NPs sample was $2162 \mathrm{~nm}$, and was comparable to the average size for the $\mathrm{ZnO}+1 \% \mathrm{Ag}$ sample. In the suspension obtained in human saliva, the size of the $\mathrm{ZnO}, \mathrm{ZnO}+0.1 \% \mathrm{Ag}$ and $\mathrm{ZnO}+10 \% \mathrm{Ag}$ agglomerates was about $340-380 \mathrm{~nm}$, while the agglomerate sizes for the $\mathrm{ZnO}+10 \% \mathrm{Ag}$ and $\mathrm{Ag}$ NPs samples were $563 \mathrm{~nm}$ and $616 \mathrm{~nm}$, respectively. It must be underlined that the average size determined by the DLS method refers to the diameter of the sphere, which is the socalled hydrodynamic diameter, while the obtained result is the average size of the particles, agglomerates and aggregates. Therefore, when the tested NPs/agglomerates/aggregates deviated from the adopted shape assumptions, an increase in the standard deviation and in the polydispersity index was observable for the tested samples.

The obtained value of $\mathrm{ZnO}$ NPs zeta potential in deionised water for $\mathrm{pH} \approx 7$ was identical to that reported in the literature, i.e. approx. $35 \mathrm{mV}^{54}$ The appearance of $\mathrm{Ag}$ NPs in the $\mathrm{ZnO} \mathrm{NP}$ suspension caused a fixed and declining trend in the zeta potential value up to $0.5 \mathrm{mV}$ for the $\mathrm{ZnO}+10 \% \mathrm{Ag}$ sample. The zeta potential of the Ag NPs sample in the deionized water
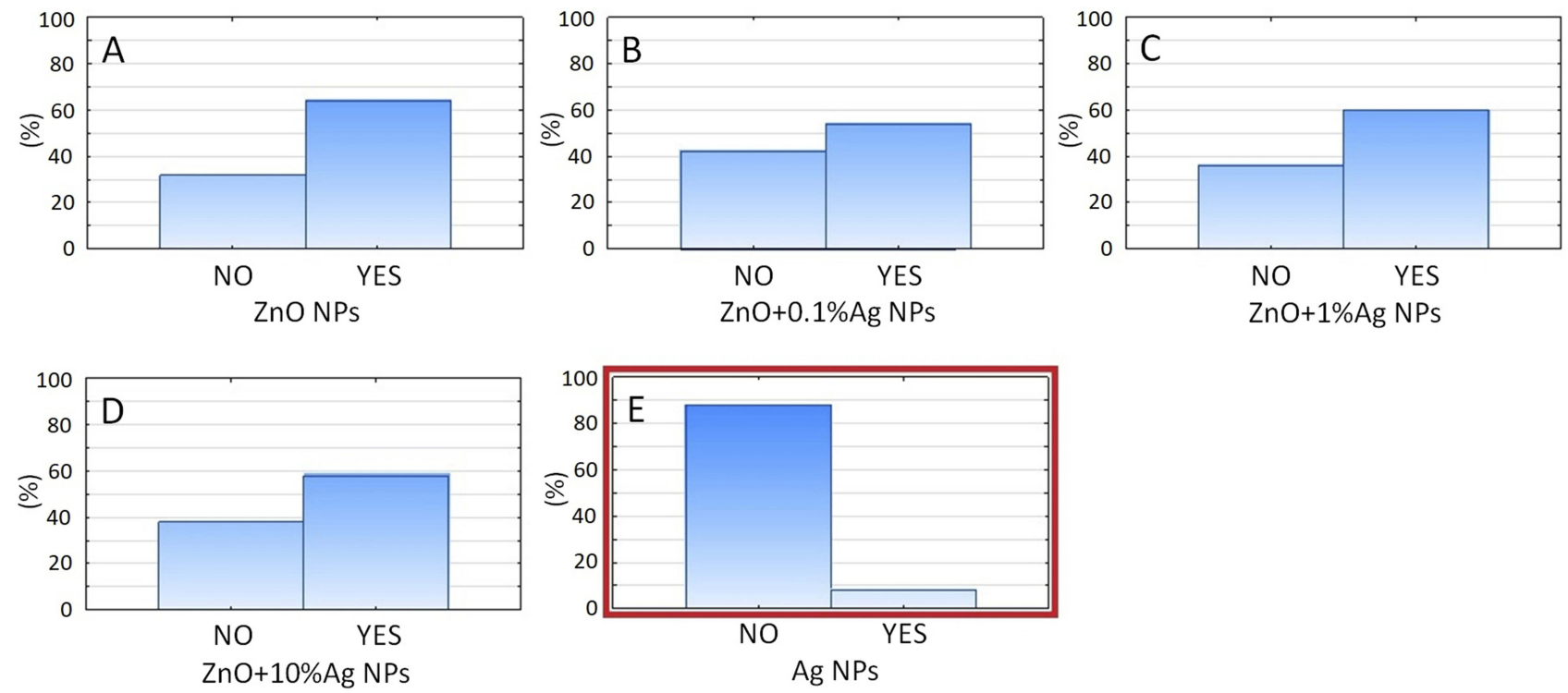

Figure 5 A categorized histogram of the overall percentage of inhibited (NO) and grown (YES) bacterial species depending on the type of solution used: (A) ZnO NPs, (B) $\mathrm{ZnO}+0.1 \% \mathrm{Ag},(\mathbf{C}) \mathrm{ZnO}+1 \% \mathrm{Ag}$, (D) $\mathrm{ZnO}+10 \% \mathrm{Ag}$, (E) Ag (Figures SI6 and SI7). It can be seen that only pure Ag NPs (E) provided significant antibacterial properties against all tested oral bacteria $(p=0.000)$.

Abbreviations: $\mathrm{ZnO}$, zinc oxide; $\mathrm{Ag}$, silver. 
Table 4 Obtained Suspensions Of Nanoparticles And Their Characteristics Prior To Testing (Time $0 \mathrm{~h}$ )

\begin{tabular}{|c|c|c|c|c|c|c|c|c|c|}
\hline \multirow[t]{2}{*}{ NP Type } & \multicolumn{3}{|c|}{$\begin{array}{l}\text { Deionised Water }(\mathrm{pH}=6.93 \pm 0.05 \\
\sigma=0.07 \pm 0.01 \mu \mathrm{SS} / \mathrm{cm})\end{array}$} & \multicolumn{3}{|c|}{$\begin{array}{l}\text { Artificial Saliva }(\mathrm{pH}=6.8 \mathrm{I} \pm 0.05 \\
\sigma=3398 \pm 3 \mu \mathrm{S} / \mathrm{cm})\end{array}$} & \multicolumn{3}{|c|}{$\begin{array}{l}\text { Human Saliva }(\mathrm{pH}=7.84 \pm 0.07 \\
\sigma=436 \mathrm{I} \pm 6 \mu \mathrm{S} / \mathrm{cm})\end{array}$} \\
\hline & $\begin{array}{l}\text { Average } \\
\text { Size } \\
(\mathrm{nm})\end{array}$ & PDI & $\begin{array}{l}\text { Zeta } \\
\text { Potential } \\
(\mathrm{mV})\end{array}$ & $\begin{array}{l}\text { Average } \\
\text { Size }(\mathbf{n m})\end{array}$ & PDI & $\begin{array}{l}\text { Zeta } \\
\text { Potential } \\
(\mathrm{mV})\end{array}$ & $\begin{array}{l}\text { Average } \\
\text { Size } \\
(\mathrm{nm})\end{array}$ & PDI & $\begin{array}{l}\text { Zeta } \\
\text { Potential } \\
(\mathrm{mV})\end{array}$ \\
\hline $\mathrm{ZnO}$ & $114 \pm 2$ & $0.127 \pm 0.013$ & $33.8 \pm 0.7$ & $1644 \pm 57$ & $0.513 \pm 0.065$ & $-73.5 \pm 5.6$ & $379 \pm 18$ & $0.413 \pm 0.086$ & $-20.7 \pm 1.6$ \\
\hline $\mathrm{ZnO}+0.1 \% \mathrm{Ag}$ & $118 \pm 1$ & $0.177 \pm 0.011$ & $32.3 \pm 0.8$ & $|70| \pm 93$ & $0.547 \pm 0.047$ & $\begin{array}{l}-66.9 \\
\pm 10.2\end{array}$ & $342 \pm 16$ & $0.689 \pm 0.029$ & $-11.1 \pm 3.4$ \\
\hline $\mathrm{ZnO}+1 \% \mathrm{Ag}$ & $145 \pm 1$ & $0.197 \pm 0.015$ & $29.2 \pm 0.7$ & $2315 \pm 167$ & $0.570 \pm 0.040$ & $-75.7 \pm 5.9$ & $367 \pm 44$ & $0.518 \pm 0.100$ & $-14.2 \pm 0.9$ \\
\hline $\mathrm{ZnO}+10 \% \mathrm{Ag}$ & $642 \pm 44$ & $0.584 \pm 0.048$ & $0.5 \pm 0.1$ & $8388 \pm 1376$ & $0.898 \pm 0.085$ & $-60.1 \pm 1.2$ & $616 \pm 42$ & $0.595 \pm 0.178$ & $-|5| \pm 0.3$. \\
\hline $\begin{array}{l}\mathrm{Ag}(55 \pm 5 \mathrm{~nm} \text {, } \\
\text { HydroSilver } \\
1000)\end{array}$ & $239 \pm 8$ & $0.609 \pm 0.119$ & $-2.2 \pm 0.1$ & $2162 \pm 219$ & $0.883 \pm 0.179$ & $-22.8 \pm 0.7$ & $53 I \pm 84$ & $0.583 \pm 0.116$ & $-11.6 \pm 0.9$ \\
\hline
\end{tabular}

Abbreviations: $\mathrm{ZnO}$, zinc oxide; $\mathrm{Ag}$, silver; NPs, nanoparticles; $\sigma$, specific conductivity; $\mu \mathrm{S}$, microsiemens; nm, nanometer; mV, millivolts; PDI, polydispersity index.

was $-2.2 \mathrm{mV}$. It is assumed that the prerequisite for the stability of water dispersion of the particles (if spherical stabilisation does not work) is a zeta potential higher than $|30 \mathrm{mV}| .{ }^{55}$ If the zeta potential ranges from $-30 \mathrm{mV}$ to $30 \mathrm{mV}$, then the NPs display an agglomeration tendency. The point at which the zeta potential reaches zero and changes its sign is called the isoelectric point. At this point, dispersion is not characterised by electrostatic stability. The zeta potential for the NPs in artificial saliva exceeded $|30 \mathrm{mV}|$ for the $\mathrm{ZnO}, \mathrm{ZnO}+0.1 \% \mathrm{Ag}, \mathrm{ZnO}+1 \%$ $\mathrm{Ag}$ and $\mathrm{ZnO}+10 \% \mathrm{Ag}$ samples, i.e. they fell within the range of the theoretical electrostatic stability. The only exception here was the Ag NPs sample, where the zeta potential value in artificial saliva was approx. $-22 \mathrm{mV}$. For suspensions obtained in human saliva, the zeta potential value was below $|30 \mathrm{mV}|$ for all samples, i.e. within the range of a lack of electrostatic stability. According to the adopted range of stability, due to the zeta potential value, all samples of $\mathrm{ZnO}+\mathrm{x} \cdot \mathrm{Ag} \mathrm{NPs}$ in artificial saliva should form stable suspensions; however, the average particle size results did not show this (Table 4). The process of NPs agglomeration at the moment of their introduction to artificial saliva could have been caused by:

- a high concentration of ions (e.g. $\mathrm{Na}^{+}, \mathrm{K}^{+}, \mathrm{Ca}^{2+}, \mathrm{Mg}^{2+}$, $\mathrm{Cl}^{-}, \mathrm{SO}_{4}{ }^{2-}, \mathrm{PO}_{4}{ }^{3-}, \mathrm{CO}_{3}{ }^{2-}, \mathrm{SCN}^{-}$), which resulted in a small range of electrostatic repulsion energy by electric field screening; - the presence of macroparticles (proteins, carbohydrates) with multiple functional groups, such as $-\mathrm{OH}$, $-\mathrm{COOH},-\mathrm{NH}_{\mathrm{x}},-\mathrm{SH}$, in the saliva, which caused the formation of hydrogen bonds (also known as hydrogen bridges) between the particles/macroparticles and the various molecules.

Each of the prepared nano-formulations exhibited significant changes when exposed to the tested media. It could be seen that in the deionised water, and in both the artificial and human saliva, the nanoparticles tended to agglomerate with time (Figures 6-8). The patterns of agglomeration were remarkably diversified between the media, though. When exposed to artificial saliva, immediate agglomeration occurred in all the tested materials and continued over the $24 \mathrm{~h}$ incubation period.

Figures 6-8 present the change in the average size of the nanoparticles in deionised water, artificial saliva and human saliva, respectively. It must be underlined that these tests relate to the samples held in "dynamic conditions" and "static conditions." This means that one part of the sample volume was stirred for the whole test duration ( $24 \mathrm{~h}$ ) using the magnetic stirrer, while the remaining part was left to rest for over an hour in the silicone tubes and the measuring cell. Once an hour the whole volume was mixed together and a fresh sample portion was pumped into the measuring cell. The test conditions were similar to the conditions found in the oral cavity, i.e. e.g. a portion of the saliva is continually stirred while eating, while the remaining part, e.g. in the interdental area, remains static. The change in the average particle size in water (Figure 6, Tables S1-S5) was characterised by cyclic changes in average particle size. This means that there were several populations of various sizes of NPs agglomerates within the sample, which was caused by the varying speed of the suspension destabilisation processes in the dynamic and static states. The results for the $\mathrm{ZnO}+10 \% \mathrm{Ag}$ suspension sample stand out particularly here. After $1 \mathrm{hr}$ the average particle size had increased from approx. $600 \mathrm{~nm}$ to over $3000 \mathrm{~nm}$, while after $12 \mathrm{hrs}$ the average particle size decreased to below $500 \mathrm{~nm}$. This means that the larger NPs agglomerates were sedimented and deposited in the silicone hoses supplying the "fresh" sample portions to the 


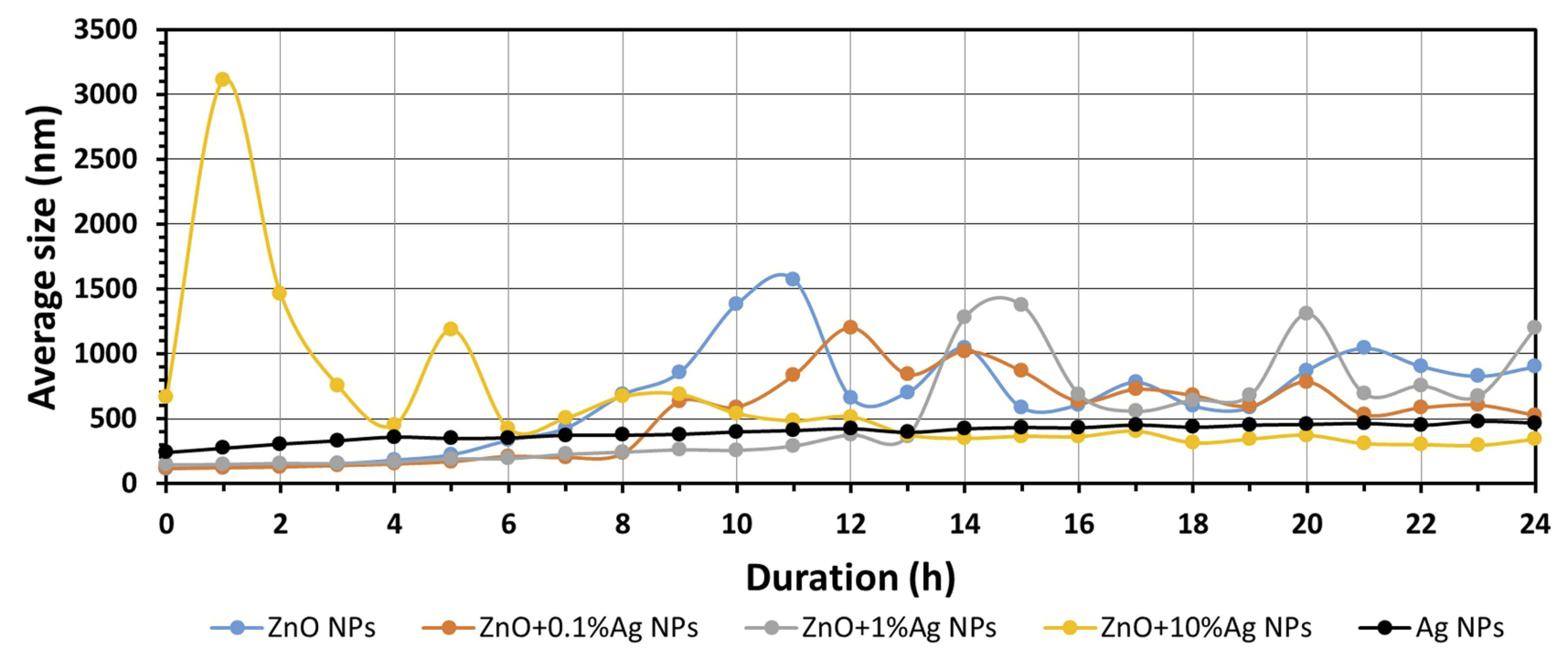

Figure 6 Results of the study of average size of NPs in deionised water as a function of time. Abbreviations: $\mathrm{ZnO}$, zinc oxide; $\mathrm{Ag}$, silver; $\mathrm{nm}$, nanometre; h, hour; NPs, nanoparticles.

measuring cell, and that the suspension flow rate was too low to completely mix the deposited NPs agglomerates with the "fresh" portion of the suspension. Generally, based on the obtained results of the average particle size, it can be stated that the $\mathrm{ZnO}, \mathrm{ZnO}+0.1 \% \mathrm{Ag}, \mathrm{ZnO}+1 \% \mathrm{Ag}$ and $\mathrm{ZnO}+10 \% \mathrm{Ag}$ samples underwent agglomeration and sedimentation processes during the test. Only the Ag NPs suspension sample displayed a steady growth in particle size without signs of cyclic changes in the results, which means that they were not deposited in the measurement system. It must be underlined that Ag NPs were the only ones that were modified and had a PVA coating, which considerably contributed to their suspension stability. For the samples of $\mathrm{ZnO}, \mathrm{ZnO}+0.1 \% \mathrm{Ag}$, $\mathrm{ZnO}+1 \% \mathrm{Ag}$ and $\mathrm{Ag}$ suspensions obtained in the artificial saliva (Figure 7, Tables S6-S10), an identical trend is visible, namely the average size increased from approx. $2000 \mathrm{~nm}(0 \mathrm{~h})$ to over $4000 \mathrm{~nm}$ (24h). Only $\mathrm{ZnO}+10 \% \mathrm{Ag}$ NPs in the artificial saliva underwent a rapid agglomeration process, and already after the first hour of the test the average size was greater than $10,000 \mathrm{~nm}$, ie greater than the maximum measuring range of the DLS analyser. In the case of the results obtained for human saliva (Figure 8, Tables S11-S15), after one hour of the test an identical trend was noticeable, i.e. a decrease in the particle size for the $\mathrm{ZnO}, \mathrm{ZnO}+0.1 \% \mathrm{Ag}, \mathrm{ZnO}+10 \% \mathrm{Ag}$ and $\mathrm{Ag}$ samples. $\mathrm{A}$

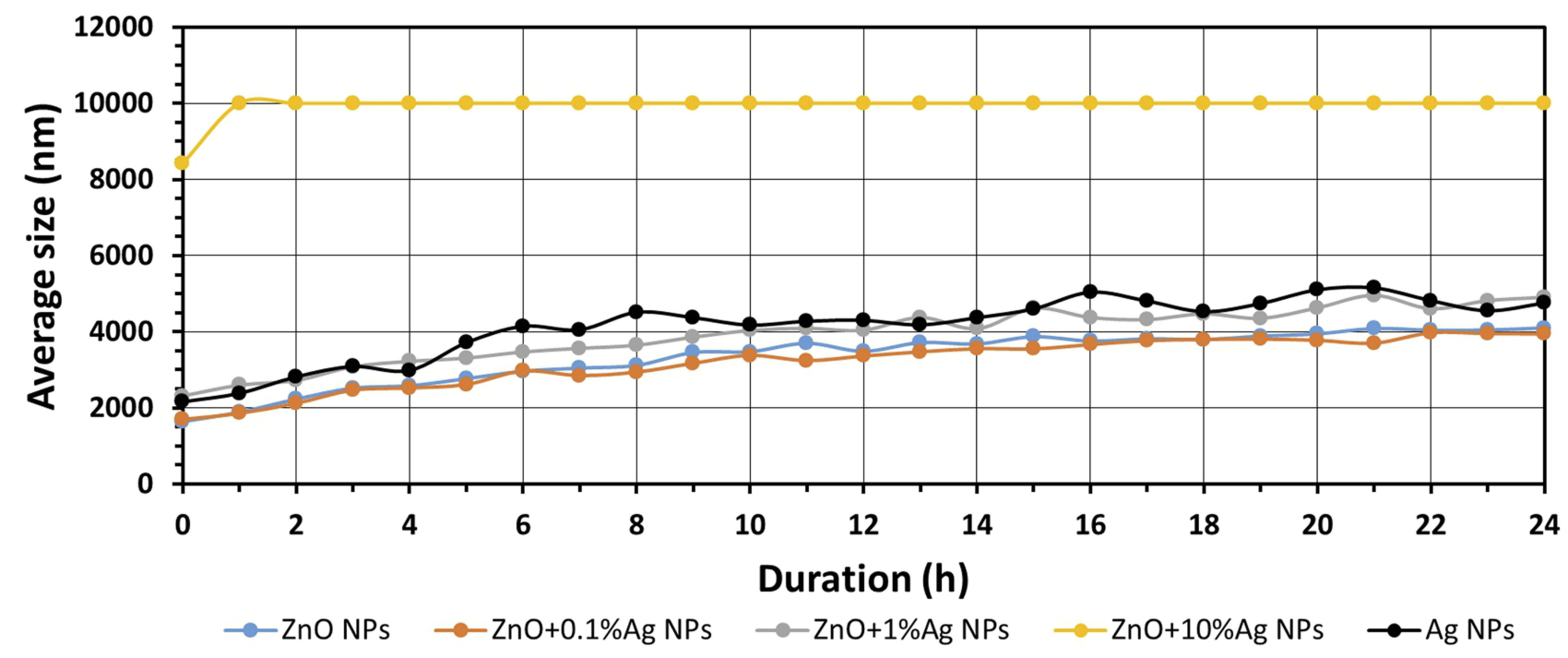

Figure 7 Results of the study of average size of NPs in artificial saliva as a function of time. Abbreviations: $\mathrm{ZnO}$, zinc oxide; Ag, silver; nm, nanometre; h, hour; NPs, nanoparticles. 


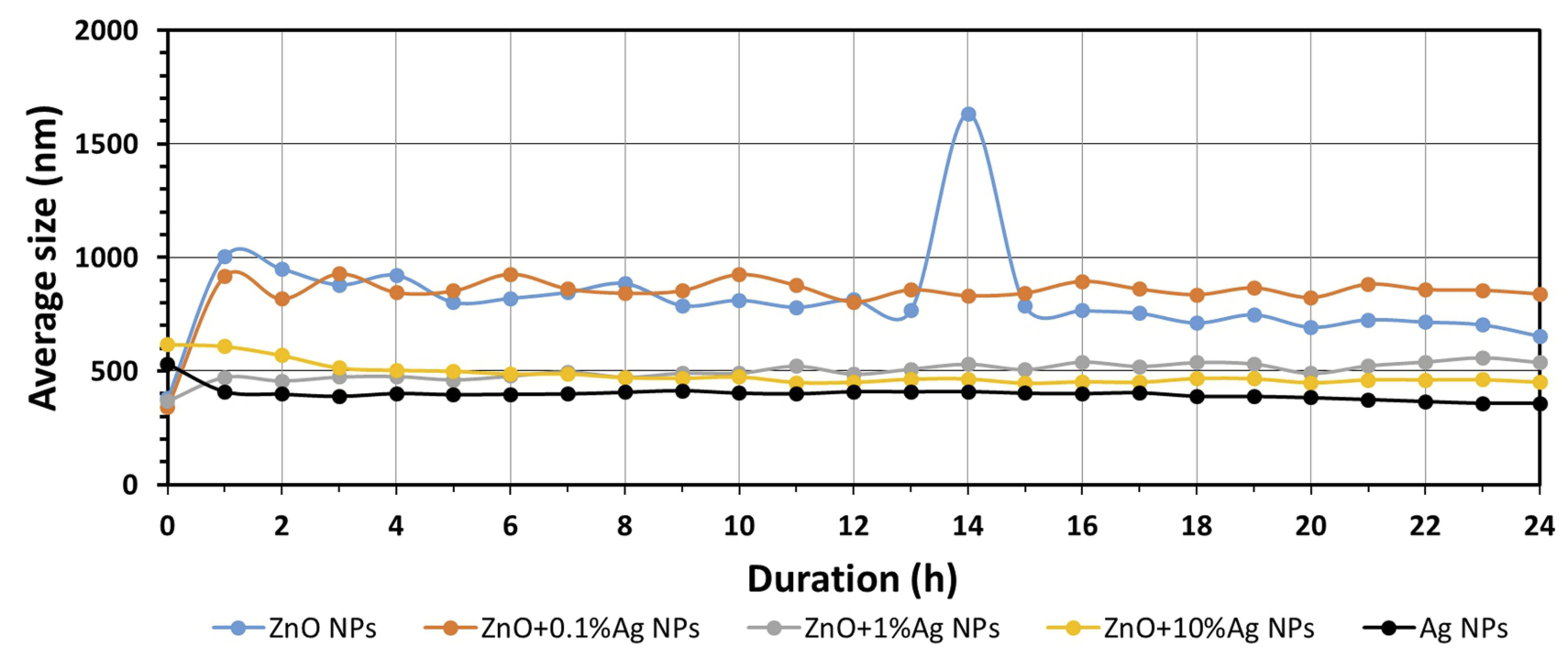

Figure 8 Results of the study of average size of NPs in human saliva as a function of time. Abbreviations: $\mathrm{ZnO}$, zinc oxide; $\mathrm{Ag}$, silver; $\mathrm{nm}$, nanometre; h, hour; NPs, nanoparticles.

slight increase in the average particle size was observed only in the $\mathrm{ZnO}+1 \% \mathrm{Ag}$ sample.

Figure 9 presents the stability profile of the sample of $\mathrm{ZnO}$ NPs suspension in human saliva. The remaining stability profile results are included in the supplementary files (Figures S1-S15). It must be borne in mind that the stability was measured in the "static" state, i.e. after closing the glass bottle, mixing and placing in the Turbiscan Lab analyser, the sample was not touched until the finish of the measurement process. Changes in the particle size and sedimentation were observed in each sample over the $24 \mathrm{hr}$ analysis period (Figure 9, Figures S1-S15). The smallest changes in stability occurred for the suspensions of $\mathrm{ZnO} \mathrm{NPs}, \mathrm{ZnO}+0.1 \% \mathrm{Ag}$ $\mathrm{NPs}, \mathrm{ZnO}+1 \% \mathrm{Ag}$ NPs and Ag NPs in deionised water. The largest change in stability profile was observed in the water suspension for $\mathrm{ZnO}+10 \% \mathrm{Ag} \mathrm{NPs}$, in which both rapid sedimentation and rapid agglomeration of the NPs occurred.
The collected stability profiles (Figures S1-S15) permitted calculation of the TSI parameter, which enables quick comparison and characterisation of the physical stability of the obtained suspensions. The higher the TSI value, the worse the stability of the sample. It is assumed that if the TSI value is the range 3->10, the destabilisation can be considered significant and may be noticeable to the naked eye, while if the TSI exceeds 10 the destabilisation can be considered as high and is certainly noticeable to the naked eye. Figures $10-12$ summarise the results of the TSI parameter for the analyses carried out for $24 \mathrm{~h}$. The lowest stability in all the media was recorded for $\mathrm{ZnO}+10 \% \mathrm{Ag}$ NPs. The Ag NPs were the most stable NPs in deionised water and in artificial saliva, while the highest stability in human saliva was displayed by the $\mathrm{ZnO}$ $+1 \%$ Ag NPs.

In order to determine the causes of the different stabilities of NP suspensions in the two types of saliva, FT-IR

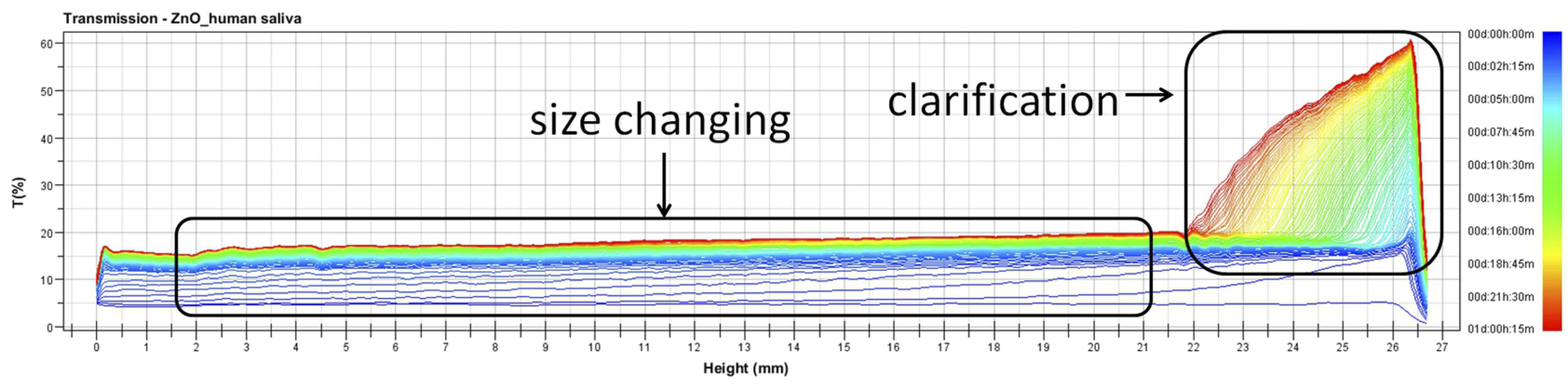

Figure 9 Transmission profile of $\mathrm{ZnO}$ NP suspension in human saliva.

Abbreviations: $\mathrm{ZnO}$, zinc oxide; mm, millimetre; h, hour; m, minute; NPs, nanoparticles; T, transmission. 


\section{Destabilisation kinetics of NPs in deionised water}

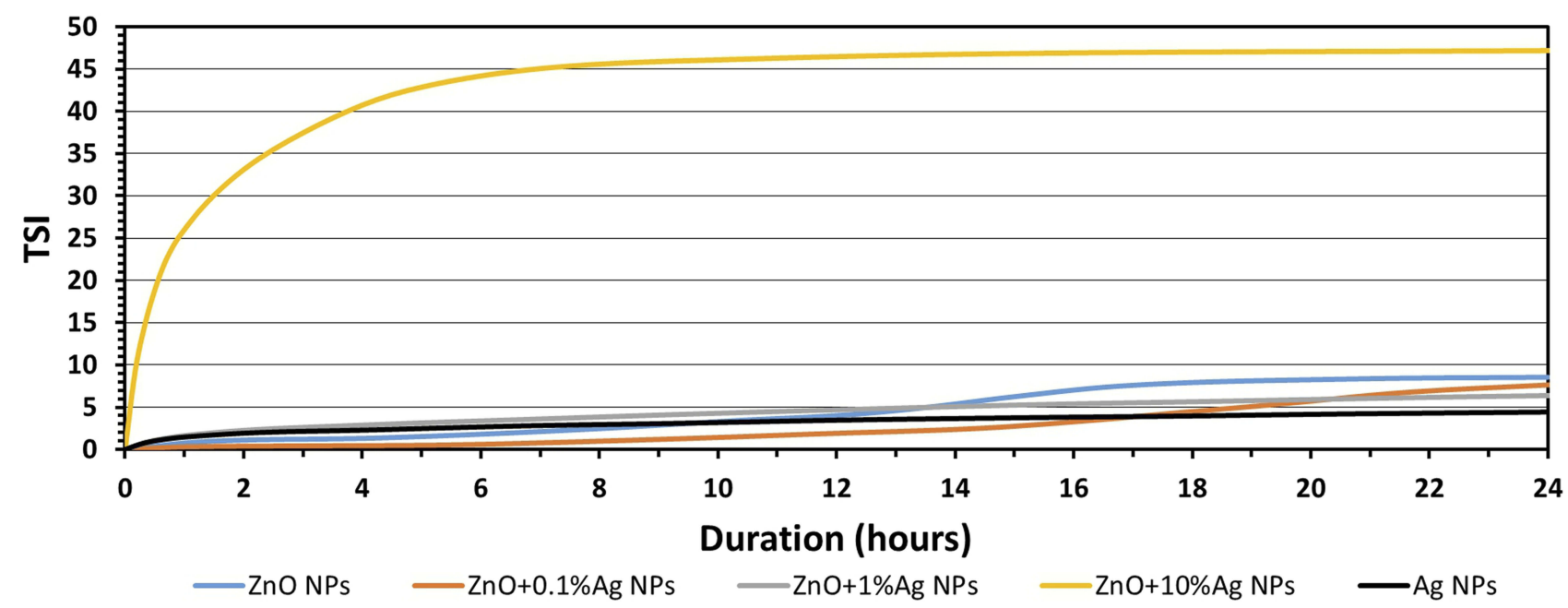

Figure 10 TSI values measured over 24 hrs for NP suspension in deionised water.

Abbreviations: $\mathrm{ZnO}$, zinc oxide; Ag, silver; NPs, nanoparticles; TSI, Turbiscan Stability Index.

analyses were performed. A representative FT-IR absorption spectrum of artificial saliva and human saliva sample is shown in Figure 13. The middle measurement range of infrared radiation (from $4000 \mathrm{~cm}^{-1}$ to $400 \mathrm{~cm}^{-1}$ ) was used, which is generally used for the qualitative analysis of lipids, proteins and carbohydrates. The characteristic bands of $3377 \mathrm{~cm}^{-1}$ and $3275 \mathrm{~cm}^{-1}$ were due to stretching vibrations of the N-H group of the protein amides. The two bands with maximums at 2918-2916 $\mathrm{cm}^{-1}$ and 2879-2872 $\mathrm{cm}^{-1}$ were due to symmetric and asymmetric stretching vibrations of the $\mathrm{C}-\mathrm{H}$ group of the proteins and lipids. The spectral peak at $2052 \mathrm{~cm}^{-1}$ corresponded to the presence of thiocyanate $\left(\mathrm{SCN}^{-}\right)$. Basic amide bands prevailed in the range from $1700 \mathrm{~cm}^{-1}$ to $1500 \mathrm{~cm}^{-1}$. The visible absorption bands within the range from $1700 \mathrm{~cm}^{-1}$ to $1600 \mathrm{~cm}^{-1}$ were due to stretching vibrations of the $\mathrm{C}=\mathrm{O}$ group of the protein amides. The presence of the $1595 \mathrm{~cm}^{-1}$ and $1535 \mathrm{~cm}^{-1}$ bands was connected with the $\mathrm{N}-\mathrm{H}$ bending vibrations of protein amides. The bands with wavenumbers of $1393 \mathrm{~cm}^{-1}$ and $1317 \mathrm{~cm}^{-1}$ were attributed to asymmetry and symmetry deformations of the protein methyl groups. The $1393 \mathrm{~cm}^{-1}$ band was probably also

\section{Destabilisation kinetics of NPs in artificial saliva}

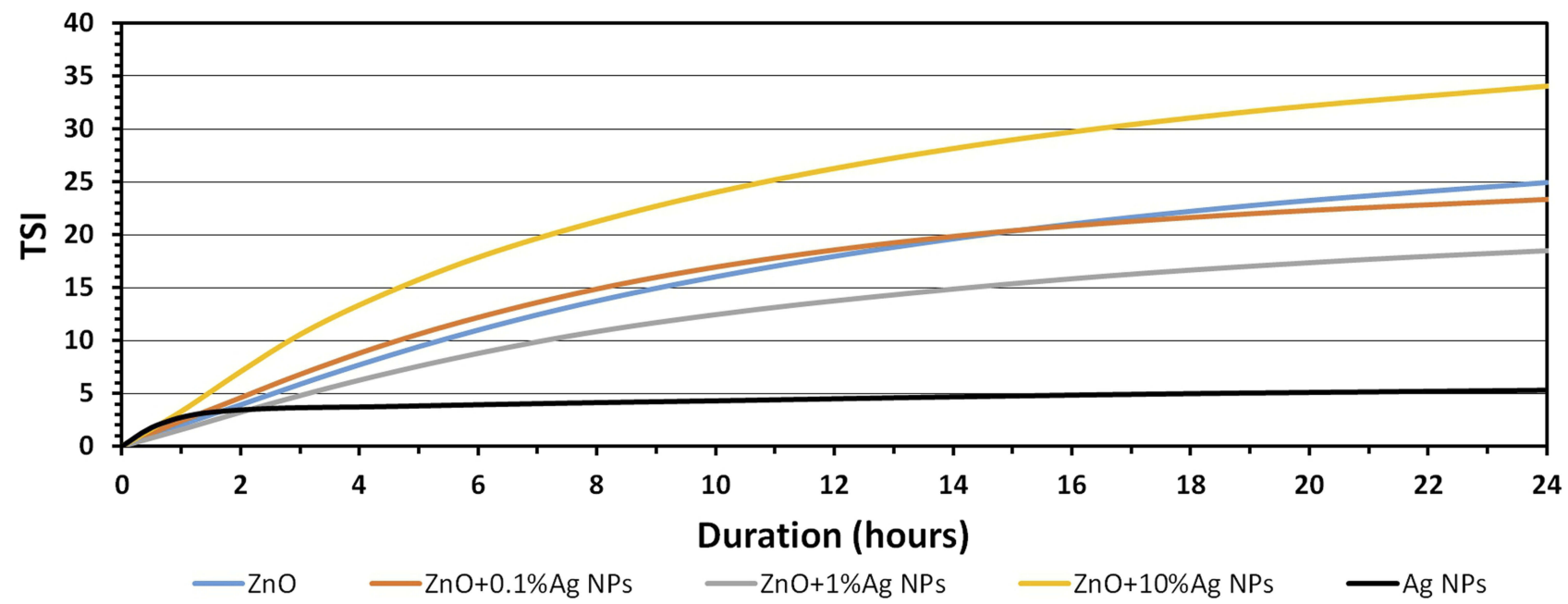

Figure II TSI values measured over 24 hrs for NP suspension in artificial saliva.

Abbreviations: $\mathrm{ZnO}$, zinc oxide; Ag, silver; NPs, nanoparticles; TSI, Turbiscan Stability Index. 


\section{Destabilisation kinetics of NPs in human saliva}

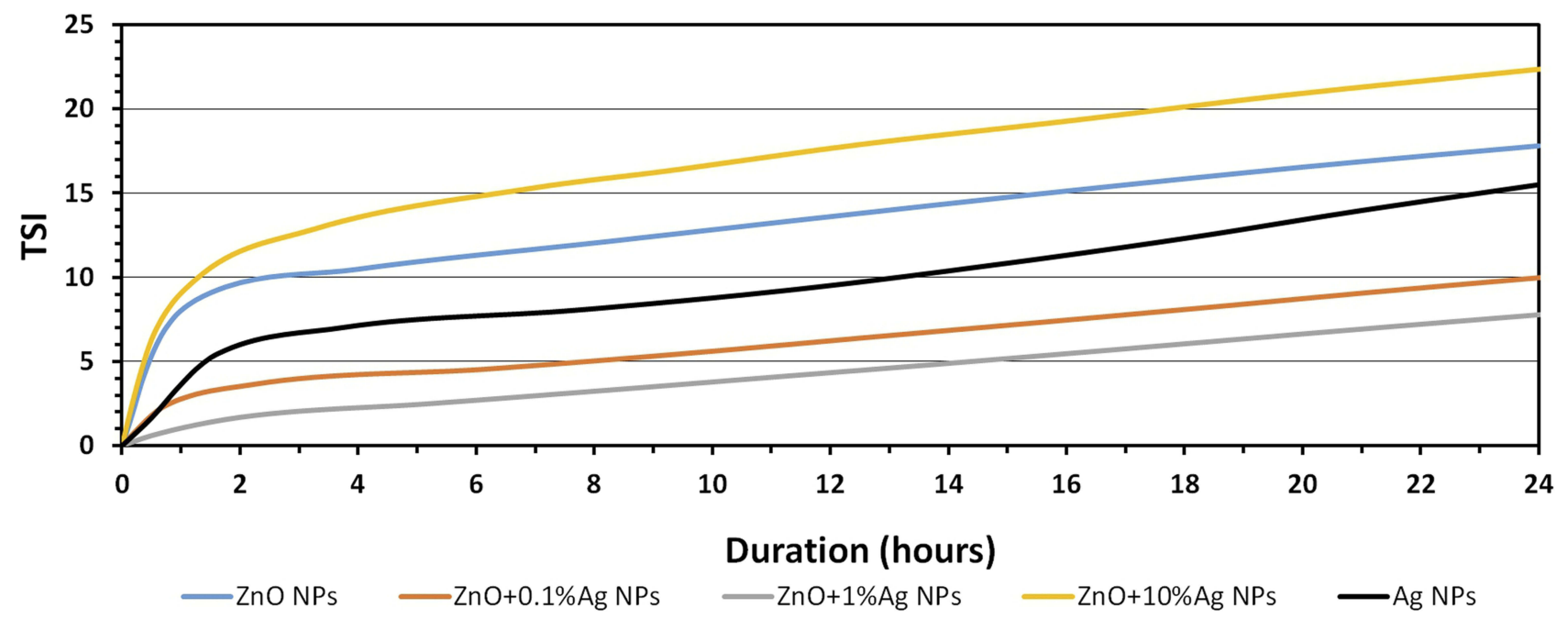

Figure 12 TSI values measured over 24 hrs for NP suspension in human saliva.

Abbreviations: $\mathrm{ZnO}$, zinc oxide; Ag, silver; NPs, nanoparticles; TSI, Turbiscan Stability Index.

due to COO- stretching of ionised amino acid chains. The bands at $1317 \mathrm{~cm}^{-1}$ were due to bending vibrations of the $\mathrm{C}$-H groups in $\alpha$ anomers, which were visible only in the artificial saliva samples. The absorption band present at 1054-1055 $\mathrm{cm}^{-1}$ was due to the different $\mathrm{C}-\mathrm{O}$ stretching vibrations of the carbohydrate structure. The detailed comparative characteristic absorption values in $\mathrm{cm}^{-1}$ for artificial saliva and human saliva are shown in Table 5.

\section{Discussion}

Zinc oxide is commonly used as a material for temporary and permanent dental biomaterials due to the beneficial effect on the healing of the hard tissues of teeth and, to a certain extent, the antibacterial properties. Use of its nanoform was proposed to enhance its biocidal properties. However, nanosilver has recently been put into many dental devices in order to decrease the infection possibility. This study investigates issues related to the antibacterial activities of zinc oxide and silver nanoparticles against the bacteria responsible for odontogenic infections in the area of the head and neck, as well as their behaviour in the saliva. The release of $\mathrm{H}_{2} \mathrm{O}_{2}$ is a possible mechanism for the antibacterial activity of $\mathrm{ZnO} \mathrm{NPs},{ }^{69}$ whereas the antibacterial activity of Ag NPs is based on cell lysis

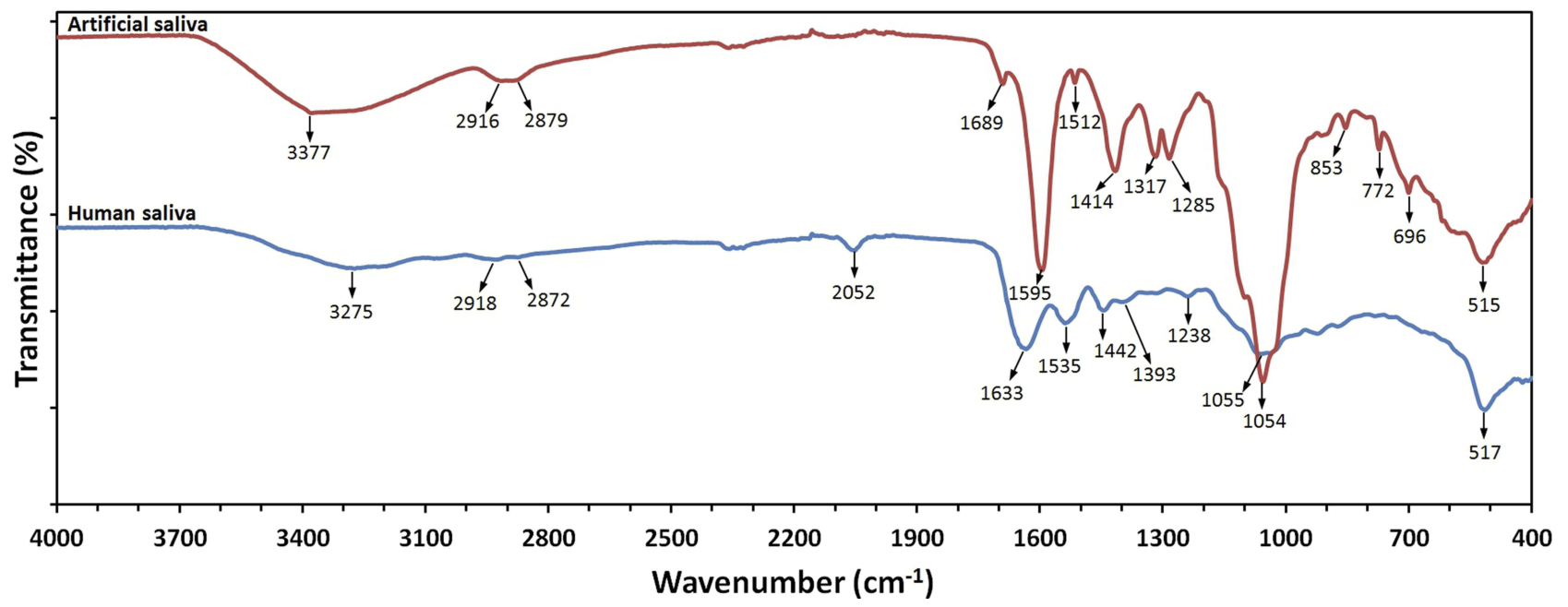

Figure 13 FT-IR spectra at RT of lyophilised samples of human saliva and artificial saliva.

Abbreviations: FT-IR, Fourier Transform Infrared Spectroscopy; RT, room temperature; \% - percentages. 
Table 5 FT-IR Spectral Assignments For Samples Of Synthetic Saliva And Human Saliva

\begin{tabular}{|c|c|c|c|}
\hline Artificial Saliva & Human Saliva & \multirow[t]{2}{*}{ Assignment } & \multirow{2}{*}{$\begin{array}{l}\text { Components Of Saliva And } \\
\text { Reference }\end{array}$} \\
\hline $\begin{array}{l}\text { Wavenumbers } \\
\left(\mathrm{cm}^{-1}\right)\end{array}$ & $\begin{array}{l}\text { Wavenumbers } \\
\left(\mathrm{cm}^{-1}\right)\end{array}$ & & \\
\hline 515 & 517 & Out of plane $\mathrm{C}=\mathrm{O}$ bending & Amide $\mathrm{VI}^{52}$ \\
\hline 696 & - & OCN bending & Amide IV $\mathrm{V}^{52}$ \\
\hline 772 & - & Out of plane $\mathrm{NH}$ bending & Amide $\mathrm{V}^{52}$ \\
\hline 1054 & 1055 & $\begin{array}{l}\text { Stretching vibrations } \mathrm{C}-\mathrm{OH} \text { and stretching vibrations in } \\
\text { carbohydrate structure of } \mathrm{C}-\mathrm{C}\end{array}$ & $\begin{array}{l}\text { Sugar moieties of glycosylated proteins, } \\
\text { including } \alpha \text {-amylase }{ }^{53,54}\end{array}$ \\
\hline- & 1238 & C-N stretching & Amide $I I I^{52,54-57}$ \\
\hline 1285 & - & C-N stretching & Amide $I I^{52,54-57}$ \\
\hline 1317 & - & $\mathrm{CH}_{2}$ vibration of $\alpha$-anomer & Carbohydrates ${ }^{58}$ \\
\hline- & 1393 & $\mathrm{CH}_{3}$ symmetric bending and $\mathrm{C}=\mathrm{O}$ stretch of $\mathrm{COO}^{-}$ & Proteins and lipids ${ }^{59-61}$ \\
\hline- & 1535 & $\mathrm{~N}-\mathrm{H}$ bending & Proteins (Amide II) ${ }^{54-56}$ \\
\hline 1595 & - & $\mathrm{N}-\mathrm{H}$ bending & Proteins (Amide II) ${ }^{52,54-56}$ \\
\hline- & 1633 & $\mathrm{C}=\mathrm{O}$ stretching & Proteins (Amide I) ${ }^{54-58}$ \\
\hline 1689 & - & $\mathrm{C}=\mathrm{O}$ stretching & Proteins (Amide I) ${ }^{52,54-58}$ \\
\hline- & 2052 & Thiocyanate $\left(\mathrm{SCN}^{-}\right)$anions & $\begin{array}{l}\text { Product of detoxication of } \mathrm{CN}^{-} \text {acquired } \\
\text { with food } \\
54,62,63\end{array}$ \\
\hline 2879 & 2872 & Symmetric vibration of $\mathrm{C}-\mathrm{H}$ & Lipids, proteins ${ }^{54,64}$ \\
\hline 2916 & 2918 & Asymmetric vibration of $\mathrm{C}-\mathrm{H}$ & Lipids, proteins ${ }^{54,64}$ \\
\hline- & 3275 & Asymmetric stretching of $\mathrm{N}-\mathrm{H}$ and vibrations of $\mathrm{O}-\mathrm{H}$ & Proteins, Amide $A^{54-56}$ \\
\hline 3377 & - & $\begin{array}{l}\text { Stretching vibrations of } \mathrm{O}-\mathrm{H} \text { and asymmetric stretching of } \\
\mathrm{N}-\mathrm{H}\end{array}$ & Proteins, Amide $A^{58,64}$ \\
\hline
\end{tabular}

Abbreviations: FT-IR, Fourier Transform Infrared Spectroscopy; C, carbon; O, oxygen; N, nitrogen; H, hydrogen; cm, centimetre.

through the inhibition of DNA replication, expression of ribosomal and cellular proteins and interference with the electron transport chain. ${ }^{70}$

Kasraei et $\mathrm{al}^{71}$ showed that the addition of $1 \%$ of nanosilver or $1 \%$ of zinc oxide nanoparticles to a composite resin resulted in antibacterial properties against $S$. mutans and Lactobacillus Acidophilus. Moreover, they showed that zinc oxide NPs were significantly more effective against $S$. mutans than nanosilver. According to another study, Salem et al, ${ }^{70}$ zinc oxide nanoparticles inhibit adenylyl cyclase activity leading to the decade of the second messenger in the process of biofilm formation. In this study, biofilm formation was not evaluated, but the zinc oxide nanoparticles used as the sole antibacterial agent were significantly inferior to hydrosilver, which confirmed other observations that Zn NPs exhibited a relatively low antibacterial capacity. ${ }^{72,73}$ The addition of either $0.1 \%, 1 \%$ or $10 \%$ of silver to Zn NPs significantly increased their antibacterial capacity against all the investigated species. Interestingly, this effect was not related to the percentage of $\mathrm{Ag}$ added. The MIC values decreased threefold (from 125 ppm up to $32 \mathrm{ppm}$ ) when silver was used as a compound (Supplementary materials). Observations taken from microbiological studies confirmed the high antimicrobial potential of nanosilver and its compounds against bacteria that are commonly responsible for odontogenic infections of the head and neck, described in prior research. ${ }^{11,74}$ Indeed, when properly applied, NPs may find a real application as an antibacterial agent able to reduce the spread of MDR species and reduce the incidence rate of nosocomial infections. As NPs and their ions released from metallic materials may provide a high antibacterial activity in the peri-implant space, such materials are expected to be applicable as drug containing implants used in sites at greater risk of infection development. ${ }^{75}$

Nevertheless, it is well known that nanoparticles with high antimicrobial properties may also exert a toxic effect on the host's tissues due to reactivity and mostly through reactive oxygen species (ROS) formation. Therefore, the therapeutic window for each nanoparticle-eluting biomaterial should be evaluated first. It may be calculated only when the biological interactions of NPs in the specific environment are taken into account. Each tissue and organ has its unique microenvironment composed of proteins, sugars, microand macroelements, which provide homeostasis when balanced. The introduction of NPs into this environment may exert an impact on this homeostasis and contribute to 
an unpredictable reaction on the part of the living organism, such as inflammatory response, irritation, rash or even carcinogenic effect when exposure is prolonged. Therefore, any biological reaction of the human body to a chemical agent that is not fully profiled must be taken into account. Nanoparticles, when detached from the material's surface, are suspended in the biological fluids and interact with its compounds, changing their conformation, reactivity and physicochemical properties. The complexes formed by NPs with proteins and sugars are described as protein coronas (PCs). As PCs travel through the body, interactions with different molecules occur and the coronas may dissolve, form conglomerates or even new compounds with unique properties. This process is known as "from synthetic to biological identity" and describes changes from the NPs properties designed in the laboratory to those gained by their interaction with a specific biological environment. This means that any NPs exposed to the body may form biological medium-related, unique coronas, which exert some impact on both antibacterial and toxicological activities. Several studies have attempted to elucidate these complex phenomena, but the vast majority of the studies focused on interactions between nanoparticles and blood plasma. ${ }^{76-78}$ Several factors play a role in the whole interaction process between NPs and protein-rich biological fluids. Lundqvist et al. ${ }^{12}$ showed that the size of the NPs influenced this process due to the curvature effect in human blood serum. They proved this in a study where silica nanoparticles of the same type but of various sizes differently influenced the binding of A-lipoprotein from human blood. The smaller the NPs, the greater the number of proteins that bound as PCs. Also, they showed that the bigger the NP size, the more up-regulated the thrombin-generation assay. The authors, therefore, showed that the same NPs, but of various sizes, may affect the organism response in different ways. Also, Ajdar et al. ${ }^{76}$ showed that gold nanoparticles added to human blood generated a faster prothrombotic response (in a nonlinear size dependent manner). They also showed the concentration dependent manner of the prothrombogenic effects and reduction of time until initial clot formation. Moreover, they noticed that clot strength decreased significantly in line with the size of the NPs added. $^{76}$

The aforementioned studies confirmed the extreme diversification of the interactions between NPs and biological fluids. Few studies have yet evaluated PC formation in the oral cavity, or sufficiently explained their impact on the oral mucosa and its permeability. ${ }^{3}$ Moreover, the results obtained in human blood serum or whole blood models cannot be transferred straightforward to the saliva, as it is a hypotonic fluid with low ionic strength, containing calcium, phosphate, carbonate, thiocyanate ions, proteins and mucin, which ensure its gel-like structure and viscoelastic properties. Moreover, approximately $73 \%$ of the salivary proteins are not present in the plasma, which implies a necessity for meticulous studies on this interaction model, especially as the oral cavity is a significant administration route for NPs. Therefore, an attempt to profile the PCs formed in the human saliva by two of the most widely used nanoparticles: silver and zinc oxide, was made in this study, because to the authors' best knowledge it was a crucial step towards a better understanding of the real potentials and limitations of nanodentistry and its current approaches. ${ }^{79,80}$ As nanoparticles introduced into the body via oral route will interact with the saliva and its molecules, PCs of distinct conformation and physicochemical properties depending on nanoparticle type are expected to occur. Such PCs may exert different effects on the tissues of the oral cavity, including the lining mucosa, gingiva, teeth and others, leading to unexpected local outcomes. NPs may penetrate the oral mucosa and travel throughout the body by the passive diffusion, blood circulatory or lymphatic systems, be deposited in the organs, penetrate cell membranes, accumulate in the mitochondria, and trigger injurious responses. ${ }^{81}$ Otherwise, materials containing NPs and placed beneath the tissues may adversely affect them.

It was shown that the morphology of nanoparticles exposed to saliva or any other biological fluids may change, depending on the fluid's $\mathrm{pH}$ and composition. In the presence of a biological fluid characterised by a neutral $\mathrm{pH}$ and high ionic strength, NPs may immediately start to aggregate and continue this process over a prolonged contact period, caused by the diminishing electrostatic repulsion between NPs and hydrophobic interactions. ${ }^{82,83}$ Differences in affinity to agglomeration between different NPs are caused by the ionic strength level of the medium and the nanoparticles properties per se, such as size, distribution, shape, crystal structure, chemical composition, surface area, functional groups, charge or porosity and stabilisers. ${ }^{83}$ Depending on the NPs charge and stability gained in silico, the nanoparticles may be unstable in the presence of proteins or even precipitate to macroscopically detected agglomerates. ${ }^{83}$ Such agglomerates may significantly mediate the cellular responses, cell uptake and the mechanism of endocytosis, biodistribution, circulation duration, clearance and permeation of the oral mucosa. ${ }^{82}$ In the study by Halamoda-Kenzaoui et al. ${ }^{84}$ the agglomeration 
level of NPs contributed to increased cellular uptake and modified endocytosis mechanisms. Dispersed $80 \mathrm{~nm}$ particles were more likely to be up-taken by cells through caveolaemediated endocytosis, whereas those sized $30 \mathrm{~nm}$ entered the cells via a combination of different endocytic pathways such as clathrin-mediated endocytosis and micropinocytosis. ${ }^{84}$

In the work by Teubl et $\mathrm{al}^{13}$ and Teubl et $\mathrm{al}^{85}$ in turn, the cellular uptake capacity of NPs after incubation in saliva was half that of a serum-free medium. Also, functionalised, positively and uncharged particles interacted to a greater extent with the salivary components than uncharged NPs. ${ }^{13,85,86}$ In a study by Walczak et $\mathrm{al}^{87}$ the sizes of the Ag NPs were stable during the $24 \mathrm{~h}$ of incubation in artificial saliva. They explained that media containing proteins may stabilise how the particles and silver nanoparticles agglomerate to a greater extent in fluids with a higher ionic strength than saliva. ${ }^{87}$ Pindakova et $\mathrm{al}^{82}$ noticed, however, that the presence of artificial saliva induced the growth of Ag NPs from $90 \pm 2$ $\mathrm{nm}$ immediately after mixing to $248 \pm 8$, measured after 180 mins in contact with the medium. Regardless of the agglomeration process, they did not observe any cytotoxic effect of the nanosilver agglomerates in reconstructed oral cavity cell lines. Moreover, Ag NPs were reported to downregulate the production of inflammatory cytokine IL-1 $\alpha$ and, therefore, show anti-inflammatory properties. This is promising as nanosilver has recently been proposed as an additive to titanium oral implants in order to decrease peri-implant infections and other biomaterials used in the reconstruction of teeth and the craniofacial area. ${ }^{11}$ Discrepancies between studies show that the presence of certain proteins in the medium may induce, slow down or prevent agglomeration and imply diverse effects on the cellular uptake of NPs in different individuals.

In this study, agglomeration by all NPs in the tested media was observed. However, when exposed to artificial saliva, the NPs formed complexes that were significantly larger than their counterparts incubated in deionised water. Saliva is a highly complex biological fluid composed of water, proteins, enzymes, hormones, ions, products of the enzymatic decomposition of carbohydrates, leukocytes, bacteria and flaked-off cells of the oral cavity epithelium. ${ }^{88-92}$ It must be underlined that human saliva is characterised by a unique composition, which depends on such factors as age, gender, stress, health condition, physical effort and type of stimulants consumed (e.g. tobacco). ${ }^{58,59,66,92}$ Teubl et $\mathrm{al}^{13}$ proved that saliva was characterised by a porous structure, where the pore size ranged from $\approx 200 \mathrm{~nm}$ to $\approx 2000 \mathrm{~nm}$, while the pores were filled by a fluid of low viscosity. The critical factors influencing the agglomeration and stability of the NPs are nanoparticle type and fluid type (Table 4). It is not surprising that the NPs (apart from $\mathrm{ZnO}+10 \% \mathrm{Ag} \mathrm{NPs}$ ) displayed the lowest agglomeration and highest stability in deionised water, which featured a low content of ions and an absence of macroparticles. The low quantity of the ions in the suspension causes a broadening of the diffuse layer of ions in the "electrical double layer" surrounding the NPs, which as a consequence results in increasing the range of the electrostatic energy of repulsion. ${ }^{93}$ In other words, in the case of a low specific conductance (low ionic strengths), the electrical double layer is dispersed, thanks to which it extends "far" from the particle surface, which increases the effectiveness of the particle-particle repulsions. The lack of electrostatic stabilisation $(\zeta=0.5 \mathrm{mV})$ and the large size of the aggregates of $\mathrm{ZnO}+10 \% \mathrm{Ag}$ NPs (approx. $500 \mathrm{~nm}$ ) explain the speed of the $\mathrm{ZnO}+10 \% \mathrm{Ag}$ NPs sample sedimentation in deionised water. It is common knowledge that the higher the size of NP agglomerates/aggregates, the quicker the process of their sedimentation. Thanks to the surface modification with PVA, Ag NPs are distinguished by stability and a lack of significant changes in their average size in deionised water, even after the elapse of $24 \mathrm{~h}$. The modification of the NP specific surface with various polymers is a key strategy in obtaining stable suspensions (steric stabilisation), ${ }^{94}$ while the hydrophilic properties of polymers contribute to the emergence of additional stabilisation through the short-range repulsive hydration forces. ${ }^{95}$

A rapid increase in the average particle size (Table 4) and particle sedimentation (Figures S6-S10) were observed in all NPs suspensions obtained in artificial saliva. Similar results were obtained by Reubl et $\mathrm{al}^{13}$ in that they proved that from among all the media used in the tests, NPs underwent the quickest agglomeration in saliva. There are two explanations for this phenomenon. The first is that high ionic strengths result in the compression and neutralisation of the diffuse layer in the electrical double layer of NPs, thanks to which the van der Waals forces cause the agglomeration of NPs. ${ }^{96,97}$ The multivalent counterions present in saliva, e.g. $\mathrm{HPO}_{4}{ }^{2-}$, $\mathrm{CO}_{3}{ }^{2-}, \mathrm{SO}_{4}{ }^{2-}$ ions, may quickly interact with the cations (or the other way round) in the adsorption layer of NPs, at the moment they are introduced to the saliva. This causes a change in the ionic composition of the electrical double layer and screening of the surface charge, which is explained by the strong interactions between the ions and counterions. The second explanation is the formation of the protein corona around NPs and their agglomerates, and the formation of hydrogen bonds between the protein corona and the particles, proteins and other various molecules. The formation of large 
nanoparticle-protein aggregates can trap proteins that do not adsorb to the nanoparticle surface, i.e. they are not part of the corona. $^{12}$ Both the interactions of the mono- and multivalent salivary ions with the electrical double layer on the surface of nanoparticles and the formation of protein coronas contribute to the agglomeration of NPs in artificial saliva, which was visible throughout the whole test duration (24h). An interesting correlation was noticeable for nanoparticles suspensions in artificial saliva: namely, the average particle size increased in line with the increase in $\mathrm{Ag}$ NPs content in the $\mathrm{ZnO}+\mathrm{x} \cdot \mathrm{Ag}$ NPs samples (Figure 7). It is likely that this correlation can be explained by the different formation of a protein corona around the particles. ${ }^{87}$ This correlation shows that Ag NPs without surface modification display no stability in the saliva whatsoever, which was indicated by the rapid agglomeration of the $\mathrm{ZnO}+10 \% \mathrm{Ag}$ sample $(>8000 \mathrm{~nm})$, characterised by the highest Ag NPs content.

It must be pointed out that the size, morphology and degree of agglomeration of the $\mathrm{ZnO}+\mathrm{x} \cdot \mathrm{Ag}$ NPs samples depend on the silver content (Figure 2). This results from the impact of the presence of Ag NPs on the course of the synthesis of $\mathrm{ZnO}$ NPs. Ag NPs are formed earlier than $\mathrm{ZnO}$ NPs, which is a consequence of the different mechanisms of reaction. Ag NPs are formed in a single-stage reaction of reduction of $\mathrm{Ag}^{+}$to metallic $\mathrm{Ag}^{\circ}$, while $\mathrm{ZnO}$ NPs are formed in a reaction where two primary stages can be distinguished. ${ }^{36}$ Namely, the formation and growth of the intermediate $\left(\mathrm{Zn}_{5}(\mathrm{OH})_{8}\left(\mathrm{CH}_{3} \mathrm{COO}\right)_{2} \cdot \mathrm{xH}_{2} \mathrm{O}\right)$ and the rapid decomposition of the intermediate to $\mathrm{ZnO} N P s$, and the growth thereof until the zinc acetate is used up. The Ag NPs formed earlier disturb the decomposition of the intermediate into individual $\mathrm{ZnO} \mathrm{NPs}$, and this is why SEM photographs show how aggregate size increases in line with increase in the Ag NPs content in the samples; this is particularly noticeable for the $\mathrm{ZnO}+10 \% \mathrm{Ag}$ sample. We observed a similar impact on the morphology and size of the microwave synthesis products when the dopant content in $\mathrm{ZnO}$ NPs increased. ${ }^{98,99}$ Obviously, one should bear in mind that the degrees of agglomeration could alter the particle degradation and circulation kinetics.

The visible change in the zeta potential by as much as $107 \mathrm{mV}$ for $\mathrm{ZnO}$ NPs in the artificial saliva relative to the $\mathrm{ZnO}$ NPs suspension in deionised water results from the formation of a new electrostatic equilibrium of the electrical double layer (Table 4). Despite the theoretical electrostatic stability arising from the zeta potential value exceeding $|30 \mathrm{mV}|$, the NPs samples displayed a lack of stability (agglomeration, sedimentation). The results obtained in these tests prove that a zeta potential value exceeding $|30 \mathrm{mV}|$ does not guarantee stability in biological fluid suspensions, which is caused mainly by the formation of the protein corona on NPs. The protein corona fulfils two primary functions: NPs destabilisation and surface inertisation. It is saliva that is the first protective mechanism of the human organism, which is supposed to reduce the activity of the NPssurface and to prevent penetration of NPs through the cell membrane in the oral cavity. Moreover, if NPs penetrate into the human organism, the protein coronas may significantly reduce their circulatory life span in the blood. ${ }^{100}$

Very interesting results were achieved for NPs suspensions in the human saliva. The transmission profiles of NPs in the artificial saliva (Figures S10-S15) showed that over the $24 \mathrm{~h}$ period the NPs underwent agglomeration and sedimentation. After $1 \mathrm{hr}$ of analyses by the DLS method, in turn, the average size of the NPs in the human saliva did not change significantly (Tables S11-S15, Figure 8). The differences in the results of suspension stability can be explained by the different manner of sample preparation before the analyser measurements. The Turbiscan Lab analyser recorded the changes in particle size and sedimentation of NPs in the suspension sample being in the static state in the measurement cell, while the DLS analyser collected a "fresh" portion of the sample every hour, which was stirred over the whole test duration using the magnetic stirrer. The results indicate that in human saliva the NPs agglomeration process features weaker forces ${ }^{53}$ and is reversible through mechanical stirring of the suspension. In comparing the composition of human saliva to the composition of artificial saliva, two primary differences are visible (Figure 13). Namely, $\mathrm{SCN}^{-}$anions were present only in the human saliva sample and the quantity of carbohydrates was considerably lower than in the artificial saliva sample. It is probable that $\mathrm{SCN}^{-}$anions were rapidly adsorbed on the surface of the NPs, in particular of the Ag particles, which might have limited or prevented permanent coating of their surface with the protein corona. The presence of thiocyanate (SCN-) anions in the saliva is quite unique. In saliva, $\mathrm{SCN}^{-}$is converted by salivary peroxidases to hypothiocyanite (OSCN-), a local antibacterial agent with high efficiency. ${ }^{101}$ It was proved that the content of thiocyanate (SCN-) anions was closely related with smoking among the participants in earlier tests, ${ }^{102}$ which indicated that some of the saliva donors were smokers.

In comparing successive and very significant saliva parameters, i.e. $\mathrm{pH}$ and specific conductance, considerable differences between artificial saliva and human saliva are noticeable 
(Table 4). As saliva samples were used from different patients, parameters such as ionic strength and $\mathrm{pH}$ could vary depending on complex interactions between the different saliva components, which give rise to the different properties of the PCs. ${ }^{103}$ Therefore, the results obtained may differ from the analytical data (artificial saliva used within this study). The literature reports ${ }^{105-107}$ that the $\mathrm{pH}$ value of human saliva depends on the stimulation process and ranges from 5.3 to 7.8. The high $\mathrm{pH}(7.84 \pm 0.07)$ obtained for the human saliva sample could be attributed to a difference in the composition of electrolytes, including a greater bicarbonate concentration, which would also explain the high specific conductance (4361 $\pm 6 \mu \mathrm{S} / \mathrm{cm})$. The differences in the zeta potential results can be explained mainly by the different $\mathrm{pH}$ and specific conductance values. It is also quite surprising that, despite the higher specific conductance and hence the greater electric field screening for human saliva, the NPs underwent slower destabilisation processes than in artificial saliva. This indicates that the protein corona of NPs that formed around the NPs in the human saliva contributed to the limitation of the destabilisation processes, hence to the improvement of their stability. Based on the results it can be stated that NPs in human saliva might maintain a relative stability while chewing, despite a zeta potential value below $|30 \mathrm{mV}|$, probably thanks to the presence of certain metabolic products and organism detoxication products, e.g. (SCN-).

Nanoparticles can penetrate into the oral cavity in several ways, e.g. as solid air pollution, as an ingredient of a medicinal product (e.g. for oral cavity rinsing) and in the form of modification of a tooth implant surface. Prolonged and repeated exposure of the oral tissues to nanoparticles may result in cumulative effects. This process is related to the exposure rate, tissue type and fluid used. ${ }^{82}$ The permeation process may be up- or down-regulated by specific enzymes. The agglomeration of NPs in the biological fluids may, however, decrease toxicity, as was shown in the study by Zook et al. ${ }^{108}$ The acidic $\mathrm{pH}$ of the fluids decreases the agglomeration of NPs with proteins, whereas alkaline $\mathrm{pH}$ up-regulates this process. In the presence of proteins in the intestinal digestion model, NPs may form complexes composed of silver, sulphur and chlorine. ${ }^{87}$ Therefore, they may aggregate and disperse as they travel throughout the body, constantly changing their properties. ${ }^{82,87}$ Also, the composition of PCs is strongly related to the competition between the proteins present in the medium to be adsorbed on the NPs surface. Protein affinity to agglomeration is also related to $\mathrm{pH}$, NPs charge, particle-protein interaction and protein identity. ${ }^{109}$ PCs may both exhibit a toxic effect or increase the biocompatibility of NPs due to conformational changes of the proteins and the agglomeration of NPs. Specific PCs and their impact on certain tissues are still unknown.

\section{Conclusions}

Nanoparticles of zinc oxide and silver form a significant group of nanomaterials characterised by antibacterial properties, which have recently begun to be widely applied in medicine. The continually growing number of new applications of $\mathrm{ZnO}$ NPs and Ag NPs, e.g. in the modification of dentures or of implant surfaces, and consequently the continuous contact of the organism with these NPs might have a potential impact on human health. Therefore, it is necessary to acquire important information about the behaviour of $\mathrm{ZnO}$ NPs and Ag NPs in biological fluid, namely saliva, which faithfully reflects the oral cavity environment.

$\mathrm{Ag}$ NPs, $\mathrm{ZnO}$ NPs and three mixtures of $\mathrm{ZnO}+\mathrm{x} \cdot \mathrm{Ag}$ NPs were used in the tests. $\mathrm{ZnO}+\mathrm{x} \cdot \mathrm{Ag}$ NPs samples were obtained thanks to the unique method of microwave solvothermal cosynthesis, which is presented for the first time. ZnO NPs and mixtures of $\mathrm{ZnO}+\mathrm{x} \cdot \mathrm{Ag}$ NPs were characterised by an average size of $30 \pm 3 \mathrm{~nm}$ and a spherical shape. The actual composition of the $\mathrm{ZnO}+0.1 \% \mathrm{Ag} \mathrm{NP}, \mathrm{ZnO}+1 \% \mathrm{Ag} \mathrm{NP}$ and $\mathrm{ZnO}+10 \% \mathrm{Ag}$ $\mathrm{NP}$ mixtures was as follows: $\mathrm{ZnO}+0.00042 \cdot \mathrm{Ag} \mathrm{NPs}, \mathrm{ZnO}$ $+0.00516 \cdot \mathrm{Ag}$ NPs and $\mathrm{ZnO}+0.0446 \cdot \mathrm{Ag}$ NPs.

Colloidal Ag NPs were most efficient in eradicating all the tested oral bacteria. The presence of small quantities of Ag NPs in the $\mathrm{ZnO}+\mathrm{x} \cdot \mathrm{Ag}$ NPs mixture almost doubled its antibacterial potential. Nanoparticles based on ZnO NPs or its compounds without Ag NPs exhibited a significantly inferior antibacterial potential when compared to Ag NPs.

The static multiple light scattering analyses indicated that all NPs suspensions, both in human saliva and in artificial saliva, underwent sedimentation and agglomeration processes over the whole test duration. Such factors as saliva composition, $\mathrm{ZnO}+\mathrm{x} \cdot \mathrm{Ag}$ NPs mixture composition and NP type all affected the kinetics of suspension destabilisation. The $\mathrm{ZnO}$ $+0.0446 \cdot$ Ag NPs sample had the highest content of unmodified Ag NPs and displayed the fastest destabilisation kinetics in all the fluids used.

The dynamic light scattering analyses indicated a rapid agglomeration process for all NPs samples at the moment they were introduced to artificial saliva. The average size of all NPs in artificial saliva gradually increased over the whole duration of the tests. The process of NPs agglomeration in artificial saliva was mainly related to the formation of the protein corona that coated the NPs surface. 
The tests of the average particle size in human saliva showed that the process of NPs agglomeration in this biological medium was reversible as a result of mechanical stirring.

\section{Ethics Statements}

This study was conducted in accordance with the Declaration of Helsinki. All patients received and signed the written informed consent, and the study was approved by the Warsaw Medical University Ethical Committee, no. KB/150/2018.

\section{Acknowledgments}

This project has been supported by AOCMF, Project AOCMFS-18-14P. A part of the research was carried out with the use of equipment funded by the CePT Project, reference: POIG.02.02.00-14-024/08, financed by the European Regional Development Fund within the Operational Programme "Innovative Economy" for 2007-2013. This work is partially supported by the National Center for Research and Development (NCBR), Poland, project iTE (STRATEGMED3/306888/3/NCBR/2017). The authors would like to thank Stanisław Gierlotka and Jan Mizeracki (Institute of High Pressure Physics of the Polish Academy of Sciences, Warsaw, Poland), and Roman Mukhovskyi. The authors would also like to thank Andrzej Stanisz, MSc (Department of Bioinformatic and Telemedicine, Jagiellonian University Medical College, Krakow, Poland) for statistical analysis of the obtained data.

\section{Disclosure}

The authors report no conflicts of interest in this work.

\section{References}

1. Aslam B, Wang W, Arshad MI, et al. Antibiotic resistance: a rundown of a global crisis. Infect Drug Resist. 2018;11:1645-1658. doi:10.2147/IDR.S173867

2. Chandki R, Kala M, Kumar KN, Brigit B, Banthia P, Banthia R. "Nanodentistry": exploring the beauty of miniature. J Clin Ex Dent. 2012;4:119-124. doi:10.4317/jced.50720

3. Pokrowiecki R, Pałka K, Mielczarek A. Nanomaterials in dentistry: a cornerstone or a black box? Nanomedicine (Lond). 2018;3(6):639667. doi: $10.2217 / \mathrm{nnm}-2017-0329$

4. Seil JT, Webster TJ. Antimicrobial applications of nanotechnology: methods and literature. Int $J$ Nanomedicine. 2012;7:2767-2781. doi:10.2147/IJN.S24805

5. Wang L, Hu C, Shao L. The antimicrobial activity of nanoparticles: present situation and prospects for the future. Int $J$ Nanomedicine. 2017;12:1227-1249. doi:10.2147/IJN.S121956

6. Mazzolini J, Weber RJM, Chen HS, et al. Protein corona modulates uptake and toxicity of nanoceria via clathrin-mediated endocytosis. Biol Bull. 2016;231:40-60. doi:10.1086/689590

7. Vasti C, Bonnet LV, Galiano MR, Rojas R, Giacomelli CE. Relevance of protein-protein interactions on the biological identity of nanoparticles. Colloid Surf B. 2018;166:330-338. doi:10.1016/j.colsurfb.2018.03.032
8. Nguyen VH, Lee BJ. Protein corona: a new approach for nanomedicine design. Int J Nanomedicine. 2017;12:3137-3151. doi:10.2147/ IJN.S129300

9. Hühn D, Kantner K, Geidel C, et al. Polymer-coated nanoparticles interacting with proteins and cells: focusing on the sign of the net charge. ACS Nano. 2013;7:3253-3263. doi:10.1021/ nn3059295

10. Paszek E, Czyz J, Woźnicka O, et al. Zinc oxide nanoparticles impair the integrity of human umbilical vein endothelial cell monolayer in vitro. J Biomed Nanotechnol. 2012;8(6):957-967. doi:10.1166/jbn.2012.1463

11. Pokrowiecki R, Zaręba T, Szaraniec B, et al. In vitro studies of nanosilver-doped titanium implants for oral and maxillofacial surgery. Int J Nanomed. 2017;12:4285-4297. doi:10.2147/IJN.S131163

12. Lundqvist $\mathrm{M}$, Augustsson $\mathrm{C}$, Lilja M, et al. The nanoparticle protein corona formed in human blood or human blood fractions. PLoS One. 2017;12(4):e0175871. doi:10.1371/journal.pone.0175871

13. Teubl BJ, Stojkovic B, Docter D, et al. The effect of saliva on the fate of nanoparticles. Clin Oral Investig. 2018;22:929-940. doi:10.1007/ s00784-017-2172-5

14. Teubl BJ, Schimpel C, Leitinger G, et al. Interactions between nano- $\mathrm{TiO}_{2}$ and the oral cavity: impact of nanomaterial surface hydrophilicity/hydrophobicity. J Hazard Mater. 2015;286:298305. doi:10.1016/J.JHAZMAT.2014.12.064

15. Kumar R, Umar A, Kumar G, Nalwa HS. Antimicrobial properties of ZnO nanomaterials: a review. Ceram Int. 2017;43:39403961 1. doi:10.1016/j.ceramint.2016.12.062

16. Wang L, Hu C, Shao L. The antimicrobial activity of nanoparticles: present situation and prospects for the future. Int $J$ Nanomedicine. 2017;12:1227-1249. doi:10.2147/IJN.S121956

17. Zhang Y, Nayak TR, Hong H, Cai W. Biomedical applications of zinc oxide nanomaterials. Curr Mol Med. 2013;13:1633-1645. doi:10.2174/1566524013666131111130058

18. Martínez-Carmona M, Gun'ko Y, Vallet-Regí M. ZnO nanostructures for drug delivery and theranostic applications. Nanomaterials. 2018;8:268. doi:10.3390/nano8040268

19. Cierech M, Kolenda A, Grudniak AM, et al. Significance of polymethylmethacrylate (PMMA) modification by zinc oxide nanoparticles for fungal biofilm formation. Int J Pharm. 2016;510(1):323335. doi:10.1016/j.ijpharm.2016.06.052

20. Cierech M, Wojnarowicz J, Szmigiel D, et al. Preparation and characterization of ZnO-PMMA resin nanocomposites for denture bases. Acta Bioeng Biomech. 2016;18(2):31-41. doi:10.5277/ABB-002322014-04

21. Cierech M, Osica I, Kolenda A, et al. Mechanical and physicochemical properties of newly formed $\mathrm{ZnO}-\mathrm{PMMA}$ nanocomposites for denture bases. Nanomaterials. 2018;8(5):305. doi:10.3390/nano8050305

22. Cierech M, Wojnarowicz J, Kolenda A, et al. Zinc oxide nanoparticles cytotoxicity and release from newly formed PMMAznO nanocomposites designed for denture bases. Nanomaterials. 2019;9(9):1318. doi:10.3390/nano9091318

23. Marambio-Jones C, Hoek EMV. A review of the antibacterial effects of silver nanomaterials and potential implications for human health and the environment. J Nanopart Res. 2010;12:1531. doi:10.1007/s11051010-9900-y

24. Pokrowiecki R, Zareba T, Mielczarek A, et al. Evaluation of biocidal properties of silver nanoparticles against cariogenic bacteria. Med Dosw Mikrobiol. 2013;65:197-206.

25. Lem KW, Choudhury A, Lakhani AA, et al. Use of nanosilver in consumer products. Recent Pat Nanotech. 2012;6:60-72. doi:10. 2174/187221012798109318

26. Vance ME, Kuiken T, Vejerano EP, et al. Nanotechnology in the real world: redeveloping the nanomaterial consumer products inventory. Beilstein J Nanotechnol. 2015;6:1769-1780. doi:10.3762/bjnano.6.181 
27. Burdușel AC, Gherasim O, Grumezescu AM, Mogoantă L, Ficai A, Andronescu E. Biomedical applications of silver nanoparticles: an up-to-date overview. Nanomaterials. 2018;8:681. doi:10.3390/ nano8090681

28. Koduru JR, Kailasa SK, Bhamore JR, Kim KH, Dutta T, Vellingiri $\mathrm{K}$. Phytochemical-assisted synthetic approaches for silver nanoparticles antimicrobial applications: a review. Adv Colloid Interface Sci. 2018;256:326-339. doi:10.1016/j.cis.2018.03.001

29. Ioan-Avram N, Anton F, Maria S, Denisa F, Ovidiu O, Ecaterina A. Silver based materials for biomedical applications. Curr Org Chem. 2014;18:173-184. doi:10.2174/ 13852728113176660141

30. Zhang XF, Liu ZG, Shen W, Gurunathan S. Silver nanoparticles: synthesis, characterization, properties, applications, and therapeutic approaches. Int J Mol Sci. 2016;17(9):1534. doi:10.3390/ijms1 7091534

31. Syafiuddin A, Salmiati S, Salim MR, et al. A review of silver nanoparticles: research trends, global consumption, synthesis, properties, and future challenges. J Chin Chem Soc. 2017;64:732-756. doi:10.1002/jecs. 201700067

32. Jaworski S, Wierzbicki M, Sawosz E, et al. Graphene oxide-based nanocompositesdecorated with silver nanoparticles as anantibacterial agent. Nanoscale Res Lett. 2018;13:116. doi:10.1186/ s11671-018-2533-2

33. Ghaffari T, Hamedi-Rad F. Effect of silver nano-particles on tensile strength of acrylic resins. J Dent Res Dent Clin Dent Prospects. 2015;9:40-43. doi:10.15171/joddd.2015.008

34. Data sheet of HydroSilver 1000. Available from: http://amepox. com.pl/wp-content/uploads/2016/02/HYDROSILVER_1000_US pdf. Accessed January 10, 2019.

35. Wojnarowicz J, Opalinska A, Chudoba T, et al. Effect of water content in ethylene glycol solvent on the size of $\mathrm{ZnO}$ nanoparticles prepared using microwave solvothermal synthesis. J Nanomater. 2016;2016:2789871. doi:10.1155/2016/2789871

36. Wojnarowicz J, Chudoba T, Koltsov I, Gierlotka S, Dworakowska S, Lojkowski W. Size control mechanism of $\mathrm{ZnO}$ nanoparticles obtained in microwave solvothermal synthesis. Nanotechnology. 2018;29(6):065601. doi:10.1088/1361-6528/aaa0ef

37. Wojnarowicz J, Chudoba T, Gierlotka S, Lojkowski W. Effect of microwave radiation power on the size of aggregates of $\mathrm{ZnO}$ NPs prepared using microwave solvothermal synthesis. Nanomaterials. 2018;8(5):343. doi:10.3390/nano8050343

38. Wojnarowicz J, Chudoba T, Gierlotka S, Sobczak K, Lojkowski W. Size control of cobalt-doped zno nanoparticles obtained in microwave solvothermal synthesis. Crystals. 2018;8(4):179. doi:10.3390/cryst8040179

39. Majcher A, Wiejak J, Przybylski J, Chudoba T, Wojnarowicz J. A novel reactor for microwave hydrothermal scale-up nanopowder synthesis. Int J Chem React Eng. 2013;11(1):361-368. doi:10.151 5/ijcre-2012-0009

40. Dąbrowska S, Chudoba T, Wojnarowicz J, Łojkowski W. Current trends in the development of microwave reactors for the synthesis of nanomaterials in laboratories and industries: a review. Crystals. 2018;8(10):379. doi:10.3390/cryst 8100379

41. Pielaszek R. FW15/45M method for determination of the grain size distribution from powder diffraction line profile. $J$ Alloy Compd. 2004;37:128-132. doi:10.1016/j.jallcom.2004.05.040

42. Nanopowder XRD processor demo, pre $\alpha$ ver.0.0.8, (C) Pielaszek research. Available from: http://science24.com/xrd. Accessed January 10, 2019.

43. FW1/5 4/5M method of evaluation of Grain Size Distribution by powder diffraction. Available from: http://science24.com/fw145m Accessed January 10, 2019.
44. Quirantes A, Arroyo F, Quirantes-Ros J. Multiple light scattering by spherical particle systems and its dependence on concentration: a T-matrix study. J Colloid Interf Sci. 2001;240:78-82. doi:10.1006/ jcis. 2001.7641

45. Menguala O, Meuniera G, Cayréa I, Puecha K, Snabre P. TURBISCAN MA 2000: multiple light scattering measurement for concentrated emulsion and suspension instability analysis. Talanta. 1999;50:445-456. doi:10.1016/S0039-9140(99)00129-0

46. Feng H, Kang W, Wu H, et al. Study on the relationship between emulsion stability and droplet dynamics of a spontaneous emulsion for chemical enhanced oil recovery. J Disper Sci Technol. 2018;39:1214. doi:10.1080/01932691.2017.1391699

47. Sun C, Liu R, Wu T, et al. Combined superfine grinding and heatshearing treatment for the microparticulation of whey proteins. Food Bioprocess Tech. 2016;9:378-386. doi:10.1007/s11947-015-1629-2

48. Liu ZQ, Yang X, Zhang Q. TURBISCAN: history, development, application to colloids and dispersions. Adv Mat Res. 2014;936:15921596. doi:10.4028/www.scientific.net/AMR.936.1592

49. Wiśniewska M. Influences of polyacrylic acid adsorption and temperature on the alumina suspension stability. Powder Technol. 2010;198(2):258-266. doi:10.1016/j.powtec.2009.11.016

50. Bykkam S, Ahmadipour M, Narisngam S, Kalagadda VR, Chakra Chidurala S. Extensive studies on X-ray diffraction of green synthesized silver nanoparticles. Adv Nanopart. 2015;4:1-10. doi:10.4236/anp.2015.41001

51. Birnboim A, Gershon D, Calame J, et al. Comparative study of microwave sintering of zinc oxide at 2.45, 30, and $83 \mathrm{GHz}$. Am Ceram Soc. 1998;81:1493-1501. doi:10.1111/j.1151-2916.1998.tb02508.x

52. The National Standards Authority of Ireland. Nanotechnologies Vocabulary - Part 2:Nano-objects (ISO/TS 80004-2:2015). Irish Standard Recommendation; S.R. CEN ISO/TS 80004-2:2017. Available from: https://infostore.saiglobal.com/preview/ 258622318982.pdf?sku=880589_SAIG_NSAI_NSAI_2092005. Accessed November 18, 2019.

53. Marsalek R. Particle size and Zeta Potential of $\mathrm{ZnO}$. APCBEE Procedia. 2014;9:13-17. doi:10.1016/j.apcbee.2014.01.003

54. Muller RH, Jacobs C, Kayser O. Nanosuspensions as particulate drug formulations in therapy. Rationale for development and what we can expect for the future. Adv Drug Del. 2001;47:3-19. doi:10.1016/S0169-409X(00)00118-6

55. Talari ACS, Martinez MAG, Movasaghi Z, Rehman S, Ur Rehman I. Advances in Fourier transform infrared (FTIR) spectroscopy of biological tissues. Appl Spectrosc Rev. 2016;52:456506. doi:10.1080/05704928.2016.1230863

56. Schultz CP, Ahmed MK, Dawes C, Mantsch HH. Thiocyanate levels in human saliva: quantitation by Fourier transform infrared spectroscopy. Anal Biochem. 1996;240:7-12. doi:10.1006/abio.1996.0323

57. Suresh S, Karthikeyan S, Jayamoorthy K. FTIR and multivariate analysis to study the effect of bulk and nano copper oxide on peanut plant leaves. J Sci Adv Mat Devices. 2016;1:343-350. doi:10.1016/j.jsamd.2016.08.004

58. Jesline A, John NP, Narayanan PM, Vani C, Murugan S. Antimicrobial activity of zinc and titanium dioxide nanoparticles against biofilmproducing methicillin-resistant Staphylococcus aureus. Appl Nanosci. 2015;5:157-162. doi:10.1007/s13204-014-0301-x

59. Salem W, Leitner DR, Zingl FG, et al. Antibacterial activity of silver and zinc nanoparticles against Vibrio cholerae and enterotoxic Escherichia coli. Int J Med Microbiol. 2015;305:85-95. doi:10.1016/J.IJMM.2014.11.005

60. Kasraei S, Sami L, Hendi S, AliKhani MY, Rezaei-Soufi L, Khamverdi Z. Antibacterial properties of composite resins incorporating silver and zinc oxide nanoparticles on Streptococcus mutans and Lactobacillus. Restor Dent Endod. 2014;39:109_ 114. doi:10.5395/rde.2014.39.2.109 
61. Aydin Sevinç B, Hanley L. Antibacterial activity of dental composites containing zinc oxide nanoparticles. J Biomed Mater Res B Appl Biomater. 2010;94:22-31. doi:10.1002/jbm.b.31620

62. Tavassoli Hojati S, Alaghemand H, Hamze F, et al. Antibacterial, physical and mechanical properties of flowable resin composites containing zinc oxide nanoparticles. Dent Mater. 2013;29:495505. doi:10.1016/j.dental.2013.03.011

63. Morita Y, Imai S, Hanyuda A, Matin K, Hanada N, Nakamura Y. Effect of silver ion coating of fixed orthodontic retainers on the growth of oral pathogenic bacteria. Dent Mater J. 2014;33:268274. doi:10.4012/dmj.2013-216

64. Pokrowiecki R. The paradigm shift for drug delivery systems for oral and maxillofacial implants. Drug Deliv. 2018;25:1504-1515. doi:10.1080/10717544.2018.1477855

65. Ajdari N, Vyas C, Bogan SL, Lwaleed BA, Cousins BG. Gold nanoparticle interactions in human blood: a model evaluation. Nanomed Nanotechnol. 2017;13:1531-1542. doi:10.1016/J. NANO.2017.01.019

66. Dobrovolskaia MA, Patri AK, Zheng J, et al. Interaction of colloidal gold nanoparticles with human blood: effects on particle size and analysis of plasma protein binding profiles. Nanomed Nanotechnol. 2009;5:106-117. doi:10.1016/j.nano.2008.08.001

67. Bode GH, Pickl KE, Sanchez-Purrà M, et al. Detection of peptide-based nanoparticles in blood plasma by ELISA. PLoS One. 2015;10:0126136. doi:10.1371/journal.pone.0126136

68. AlKahtani RN. The implications and applications of nanotechnology in dentistry: a review. Saudi Dent J. 2018;30:107-116. doi:10.1016/J.SDENTJ.2018.01.002

69. Şuhani MF, Băciuţ G, Băciuţ M, Şuhani R, Bran S. Current perspectives regarding the application and incorporation of silver nanoparticles into dental biomaterials. Clujul Med. 2018;91:274279. doi:10.15386/cjmed-935

70. Feng X, Chen A, Zhang Y, Wang J, Shao L, Wei L. Application of dental nanomaterials: potential toxicity to the central nervous system. Int J Nanomedicine. 2015;10:3547-3565. doi:10.2147/IJN.S79892

71. Pind'áková L, Kašpárková V, Kejlová K, et al. Behaviour of silver nanoparticles in simulated saliva and gastrointestinal fluids. Int $J$ Pharm. 2017;527:12-20. doi:10.1016/j.ijpharm.2017.05.026

72. Bantz C, Koshkina O, Lang $\mathrm{T}$, et al. The surface properties of nanoparticles determine the agglomeration state and the size of the particles under physiological conditions. Beilstein $J$ Nanotechnol. 2014;5:1774-1786. doi:10.3762/bjnano.5.188

73. Halamoda-Kenzaoui B, Ceridono M, Urbán P, et al. The agglomeration state of nanoparticles can influence the mechanism of their cellular internalisation. $J$ Nanobiotechnology. 2017;15:48. doi:10.1186/s12951-017-0281-6

74. Teubl BJ, Meindl C, Eitzlmayr A, Zimmer A, Fröhlich E, Roblegg E. In-vitro permeability of neutral polystyrene particles via buccal mucosa. Small. 2013;9:457-466. doi:10.1002/smll.201201789

75. Zook JM, Maccuspie RI, Locascio LE, Halter MD, Elliott JT. Stable nanoparticle aggregates/agglomerates of different sizes and the effect of their size on hemolytic cytotoxicity. Nanotoxicology. 2011;5:517-530. doi:10.3109/17435390.2010.536615

76. Walczak P, Fokkink R, Peters R, et al. Behaviour of silver nanoparticles and silver ions in an in vitro human gastrointestinal digestion model. Nanotoxicology. 2013;7:1198-1210. doi:10.3109/17435390.2012.726382

77. Humphrey SP, Williamson RT. A review of saliva: normal composition, flow, and function. J Prosthet Dent. 2001;85(2):162169. doi:10.1067/mpr.2001.113778

78. Tiwarim M. Science behind human saliva. J Nat Sci Biol Med. 2011;2(1):53-58. doi:10.4103/0976-9668.82322

79. Schenkels LC, Veerman EC, Nieuw Amerongen AV. Biochemical composition of human saliva in relation to other mucosal fluids. Crit Rev Oral Biol Med. 1995;6(2):161-175. doi:10.1177/1045 4411950060020501
80. Sanguansermsri P, Jenkinson HF, Thanasak J, et al. Comparative proteomic study of dog and human saliva. PLoS One. 2018;13 (12):0208317. doi:10.1371/journal.pone.0208317

81. Raziya Sultana R, Zafarullah SN, Hephzibah Kirubamani N. Saliva signature of normal pregnant women in each trimester as analyzed by FTIR spectroscopy. I J Sci Technol. 2011;4:481-486. doi:10.17485/ijst/2011/v4i5/30046

82. Scott DA, Renaud DE, Krishnasamy S, et al. Diabetes-related molecular signatures in infrared spectra of human saliva. Diabetol Metab Syndr. 2010;2:48. doi:10.1186/1758-5996-2-48

83. Caetano Júnior PC, Strixino JF, Raniero L. Analysis of saliva by Fourier transform infrared spectroscopy for diagnosis of physiological stress in athletes. Res Biomed Eng. 2015;31:115-124. doi: $10.1590 / 2446-4740.0664$

84. Rodrigues LM, Magrini TD, Lima CF, Scholz J, da Silva Martinho H, Almeida JD. Effect of smoking cessation in saliva compounds by FTIR spectroscopy. Spectrochimi Acta Part A. 2017;174:124-129. doi:10.1016/j.saa.2016.11.009

85. Ohshima H. Electrical Phenomena at Interfaces and Biointerfaces: Fundamentals and Applications in Nano-, Bio-, and Environmental Sciences. John Wiley \& Sons, Inc; 2012. ISBN:9780470582558. doi:10.1002/9781118135440

86. Guerrini L, Alvarez-Puebla RA, Pazos-Perez N. Surface modifications of nanoparticles for stability in biological fluids. Materials. 2018;11:1154. doi:10.3390/ma11071154

87. Moore TL, Rodriguez-Lorenzo L, Hirsch V, et al. Nanoparticle colloidal stability in cell culture media and impact on cellular interactions. Chem Soc Rev. 2015;44:6287-6305. doi:10.1039/C4 CS00487F

88. Boström M, Williams DRM, Ninham BW. Specific ion effects: why DLVO theory fails for biology and colloid systems. Phys Rev Lett. 2001;87:168103. doi:10.1103/ PhysRevLett.87.168103

89. Edwards SA, Williams DRM. Double layers and interparticle forces in colloid science and biology: analytic results for the effect of ionic dispersion forces. Phys Rev Lett. 2004;92:248303. doi:10.1103/PhysRevLett.92.248303

90. Wojnarowicz J, Mukhovskyi R, Pietrzykowska E, Kusnieruk S, Mizeracki J, Lojkowski W. Microwave solvothermal synthesis and characterization of manganese-doped $\mathrm{ZnO}$ nanoparticles. Beilstein J Nanotechnol. 2016;7:721-732. doi:10.3762/bjna no.7.64

91. Wojnarowicz J, Omelchenko M, Szczytko J. Structural and magnetic properties of Co-Mn Codoped $\mathrm{ZnO}$ nanoparticles obtained by microwave solvothermal synthesis. Crystals. 2018;8:410. doi:10.3390/cryst8110410

92. Salvati A, Pitek AS, Monopoli MP, et al. Transferrin-functionalized nanoparticles lose their targeting capabilities when a biomolecule corona adsorbs on the surface. Nat Nanotechnol. 2013;8:137-143. doi:10.1038/nnano.2012.237

93. Pruitt KM, Mansson-Rahemtulla B, Baldone DC, Rahemtulla F. Steady-state kinetics of thiocyanate oxidation catalyzed by human salivary peroxidase. Biochemistry. 1998;27(1):240-245. doi:10.10 21/bi00401a036

94. Ruth KJ, Neaton JD. Evaluation of two biological markers of tobacco exposure. MRFIT Research Group. Prev Med. 1991;20 (5):574-589. doi:10.1016/0091-7435(91)90056-A

95. Crea F, De Stefano C, Milea D, Pettignano A, Sammartano S. SALMO and S 3 M: a saliva model and a single saliva salt model for equilibrium studies. Bioinorg Chem Appl. 2015;2015:267985. doi:10.1155/2015/267985

96. Kazakov VN, Udod AA, Zinkovych II, Fainerman VB, Miller R. Dynamic surface tension of saliva: general relationships and application in medical diagnostics. Colloid Surf B. 2009;74:457461. doi:10.1016/j.colsurfb.2009.06.010 
97. Aframian DJ, Davidowitz T, Benoliel R. The distribution of oral mucosal $\mathrm{pH}$ values in healthy saliva secretors. Oral Dis. 2006;12:420-423. doi:10.1111/j.1601-0825.2005.01217.x

98. Christersson CE, Lindh L, Amebrant T. Film-forming properties and viscosities of saliva substitutes and human whole saliva. Eur J Oral Sci. 2000;108:418-425. doi:10.1034/j.16000722.2000.108005418.x

99. Gittings S, Turnbull N, Henry B, Roberts CJ, Gershkovich P. Characterisation of human saliva as a platform for oral dissolution medium development. Eur J Pharm Biopharm. 2015;91:16-24. doi:10.1016/j.ejpb.2015.01.007

100. Zook JM, Maccuspie RI, Locascio LE, Halter MD, Elliott JT. Stable nanoparticle aggregates/agglomerates of different sizes and the effect of their size on hemolytic cytotoxicity. Nanotoxicology. 2011;5:517-530. doi:10.3109/17435390.2010.536615

101. Burcza A, Gräf V, Walz E, Greiner R. Impact of surface coating and food-mimicking media on nanosilver-protein interaction. $J$ Nanoparticle Res. 2015;17:428. doi:10.1007/s11051-015-3235-7

102. Carton O, Ghaymouni J, Lejeune M, Zeinert A. Optical characterization of porous sputtered silver thin films. J Spectrosc. 2013;2013:307824. doi: $10.1155 / 2013 / 307824$

103. Kong J, Yu S. Fourier transform infrared spectroscopic analysis of protein secondary structures. Acta Bioch Bioph Sin. 2007;39 (8):549-559. doi:10.1111/j.1745-7270.2007.00320.x
104. Orphanou CM, Walton-Williams L, Mountain H, Cassella J. The detection and discrimination of human body fluids using ATR FTIR spectroscopy. Forensic Sci Int. 2015;252:10-16. doi:10.1016/j. forsciint.2015.04.020

105. Khaustova S, Shkurnikov M, Tonevitsky E, Artyushenko V, Tonevitsky A. Noninvasive biochemical monitoring of physiological stress by Fourier transform infrared saliva spectroscopy. Analyst. 2010;135:3183-3192. doi:10.1039/c0an00529k

106. Andrysewicz E, Mystkowska J, Kolmas J, Jałbrzykowski M, Olchowik R, Dąbrowski JR. Influence of artificial saliva compositions on tribological characteristics of Ti-6Al-4V implant alloy. Acta Bioeng Biomech. 2012;14:71-79. doi:10.5277/abb120409

107. Ramalingam P, Reddy YP, Kumar KV, Chandu BR, Rajendran K. Evaluation of metformin hydrochloride in Wistar rats by FTIRATR spectroscopy: a convenient tool in the clinical study of diabetes. J Nat Sci Biol Med. 2014;5(2):288-292. doi:10.4103/ 0976-9668.136168

108. Orphanou CM, Walton-Williams L, Mountain H, Cassella J. The detection and discrimination of human body fluids using ATR FTIR spectroscopy. Forensic Sci Int. 2015;252:10-16. doi:10.1016/j. forsciint.2015.04.020

109. Zou Y, Xia P, Yang F, et al. Whole blood and semen identification using mid-infrared and Raman spectrum analysis for forensic applications. Anal Methods. 2016;8:3763-3767. doi:10.1039/c5ay03337c
International Journal of Nanomedicine

\section{Publish your work in this journal}

The International Journal of Nanomedicine is an international, peerreviewed journal focusing on the application of nanotechnology in diagnostics, therapeutics, and drug delivery systems throughout the biomedical field. This journal is indexed on PubMed Central, MedLine, CAS, SciSearch ${ }^{\circledR}$, Current Contents ${ }^{\circledR} /$ Clinical Medicine,

\section{Dovepress}

Journal Citation Reports/Science Edition, EMBase, Scopus and the Elsevier Bibliographic databases. The manuscript management system is completely online and includes a very quick and fair peer-review

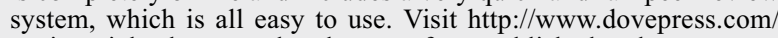
testimonials.php to read real quotes from published authors. 